\begin{tabular}{|c|l|}
\hline Title & A significant role of the totally symmetric valley-ridge inflection point in the bifurcating reaction pathway \\
\hline Author(s) & Harabuchi, Yu; Taketsugu, Tetsuya \\
\hline Citation & $\begin{array}{l}\text { Theoretical Chemistry A ccounts: Theory, Computation, and Modeling (Theoretica Chimica A cta), 130(2-3), 305-315 } \\
\text { https:/doi.org/10.1007/300214_011-0977-x }\end{array}$ \\
\hline Issue Date & 2011-10 \\
\hline Doc URL & http://hdl.handle.net/2115/50152 \\
\hline Rights & The original publication is available at www.springerlink.com \\
\hline Type & article (author version) \\
\hline File Information & TCA 130-2-3_305-315.pdf \\
\hline
\end{tabular}

Instructions for use 


\title{
A Significant Role of the Totally-Symmetric Valley-Ridge Inflection Point in the Bifurcating Reaction Pathway
}

\author{
Yu Harabuchi and Tetsuya Taketsugu \\ Division of Chemistry, Graduate School of Science, Hokkaido University, Sapporo, Hokkaido \\ 060-0810, Japan
}

\begin{abstract}
Appearance of the valley-ridge inflection (VRI) point on the intrinsic reaction path (IRP) introduces geometrical instability of the reaction coordinate, and sometimes leads to two different product minima on the potential energy surface (PES). A significant role of the totally-symmetric VRI point on the IRP is discussed from the viewpoint of branching of the reaction pathway. As illustrative examples, $a b$ initio calculations were performed to determine the IRP for $\mathrm{XCHO}^{-}+$ $\mathrm{CH}_{3} \mathrm{Cl}\left(\mathrm{X}=\mathrm{H}, \mathrm{CH}_{3}\right)$ at the Møller-Plesset second-order perturbation theory (MP2) level with $6-31+\mathrm{G}(\mathrm{d})$ basis sets, and geometric features of the PES around the IRP have been analyzed.
\end{abstract}




\section{INTRODUCTION}

Under the Born-Oppenheimer approximation [1], the processes of chemical reactions are described as the motion of atomic nuclei on the potential energy surface (PES). In theoretical study of chemical reactions, the concept of reaction path has played a significant role for understanding the reaction mechanism. Fukui introduced a mathematical definition of the reaction path for an elementary reaction of the polyatomic system, which connects the first-order saddle point (corresponding to a transition state: TS) and two minima (corresponding to reactant and product) continuously on the PES [2]. The thus determined reaction path is referred to as intrinsic reaction coordinate (IRC) or intrinsic reaction path (IRP). Once the IRP is determined for a given elementary reaction, one could estimate the reaction rate by applying the variational transition state theory with the semiclassical tunneling method [3,4] Miller, Handy, and Adams introduced the reaction path Hamiltonian for reaction-path based dynamics, which is represented in terms of a reaction coordinate, a set of transverse normal coordinates, and their conjugate momenta [5].

In the reaction-path based dynamics, there are two cases where one should explore the PES more extensively far from the IRP. The first case is a highly-curved IRP. When the IRP is sharply curved in the configurational space, there increases a curvature coupling between the reaction coordinate and the transverse vibrational coordinate, which leads to the positive and negative centrifugal forces on atoms. The positive centrifugal force invokes the excitation of vibrational motions coupled strongly with atomic motions along the reaction coordinate, while the negative centrifugal force works to push the optimal tunneling path to the corner-cutting direction from the IRP. As to the former effect, Kato and Morokuma proposed the method to predict which vibrational modes are excited through the atomic motions along the IRP [6]. Truhlar and coworkers proposed various semiclassical tunneling models even for the sharply-curved IRP $[3,4]$. One of the present authors (TT) also introduced the reaction surface model in terms of the reaction coordinate and the curvature coordinate, to determine the optimal tunneling path for a polyatomic system [7-9].

The second case is related to the instability of a reaction coordinate. When the potential-energy curvature with respect to some transverse vibrational coordinate turns its sign from positive to negative as proceeding along the IRP, geometrical feature relative to this direction is changed from the bottom of valley to the top of ridge (this point is referred to as valley-ridge inflection (VRI) point $[10,11]$ ). The negative potential-energy curvature indicates that molecular system proceeds along the ridge-path (thus, the reaction coordinate becomes unstable). Since the tangent vector of the IRP is defined in a direction of the negative energy gradient which belongs to the totally-symmetric representation of the molecular point group, the reaction coordinate is a totally-symmetric coordinate at non-stationary points [12]. According to this property, the reaction coordinate has no curvature coupling with non-totally-symmetric coordinates, and thus, VRI can be 
invoked with respect to the non-totally-symmetric vibrational coordinate (non-totally-symmetric VRI) [13]. If a ridge character of the IRP is conserved even at the terminal point, this terminal point is not a minimum but the TS which connects two symmetrically equivalent product minima with the lower symmetry. As to non-totally-symmetric VRI, there have been a lot of theoretical studies which focus on the nature of the PES [13-15], formulation of the bifurcating reaction path $[16,17]$, analyses based on the second-order Jahn-Teller (SOJT) theory [18-20], dynamics simulation $[21,22]$, and isotope effects on the bifurcating reaction pathway [22,23].

In this paper, we focus on the totally-symmetric VRI point, especially its significant role in the branching of products. In the section II, we introduce a reaction-path-based potential energy surface and describe that a projection technique to obtain vibrational frequencies along the IRP affects only the totally-symmetric vibrational modes. In the section III, we show illustrative applications to discuss the role of the totally-symmetric VRI in bifurcating reactions.

\section{VALLEY-RIDGE INFLECTION ALONG THE REACTION PATHWAY}

The IRP is defined as the steepest descent path in mass-weighted coordinates, starting from TS in both positive and negative directions of the imaginary-frequency normal mode [2]. At non-stationary points, the tangent vector of the IRP, $\mathbf{v}$, is defined by the normalized energy gradient vector in mass-weighted coordinate as

$$
\begin{aligned}
& \mathbf{v}(s)=\frac{\operatorname{grad}(V)}{|\operatorname{grad}(V)|} \quad(s<0), \\
& \mathbf{v}(s)=\frac{-\operatorname{grad}(V)}{|\operatorname{grad}(V)|} \quad(s>0),
\end{aligned}
$$

where $s$ is a reaction coordinate, and $V$ is an adiabatic potential energy. Along the IRP, we can define a set of normal mode vectors which correspond to eigenvectors of the Hessian matrix $\mathbf{H}(s)$ in mass-weighted coordinate. If the molecule has a spatial symmetry, each eigenvector of the Hessian matrix can be classified according to the irreducible representations of the molecular point group. Now we divide eigenequations of the Hessian matrix into totally-symmetric and non-totally-symmetric parts as follows,

$$
\begin{aligned}
& \mathbf{H}(s) \mathbf{L}_{i}^{\mathrm{T}}(s)=\lambda_{i}^{\mathrm{T}}(s) \mathbf{L}_{i}^{\mathrm{T}}(s), \quad\left(i=1, \ldots, n_{\mathrm{T}}\right), \\
& \mathbf{H}(s) \mathbf{L}_{i}^{\mathrm{N}}(s)=\lambda_{i}^{\mathrm{N}}(s) \mathbf{L}_{i}^{\mathrm{N}}(s), \quad\left(i=1, \ldots, n_{\mathrm{N}}\right),
\end{aligned}
$$

where $\mathbf{L}_{i}{ }^{\mathrm{T}}$ and $\mathbf{L}_{i}{ }^{\mathrm{N}}$ are normal mode vectors of total-symmetry and non-total-symmetry, respectively, $\lambda_{i}^{\mathrm{T}}$ and $\lambda_{i}^{\mathrm{N}}$ are the corresponding eigenvalues (force constants), and $n_{\mathrm{T}}$ and $n_{\mathrm{N}}$ are the number of the modes of total-symmetry and non-total-symmetry, respectively. The sum of $n_{\mathrm{T}}$ and $n_{\mathrm{N}}$ is equal to $3 N-6$ where $N$ is the number of atoms.

In the reaction-path-based dynamics for $N$ atomic system, nuclear positions are described 
in terms of a reaction coordinate and $3 N-7$ normal coordinates. To define the basis vectors for $3 N$ - 7 normal coordinates which are orthogonal to the reaction-path tangent vector $\mathbf{v}(s)$, a component of $\mathbf{v}(s)$ needs to be projected out from the Hessian matrix. Equation (5) shows a definition of the projected Hessian matrix [5],

$$
\mathbf{H}^{\mathrm{P}}(s)=\left(\mathbf{1}-\mathbf{v}(s) \mathbf{v}(s)^{t}\right) \mathbf{H}(s)\left(\mathbf{1}-\mathbf{v}(s) \mathbf{v}(s)^{t}\right) .
$$

Since the reaction coordinate belongs to the total-symmetry representation, only the totally-symmetric eigenvectors are affected by this projection. The eigenequation for totally symmetric modes in equation (3) should be replaced with the following equations,

$$
\begin{aligned}
& \mathbf{H}^{\mathrm{P}}(s) \mathbf{L}_{i}^{\mathrm{TP}}(s)=\lambda_{i}^{\mathrm{TP}}(s) \mathbf{L}_{i}^{\mathrm{TP}}(s), \quad\left(i=1, \ldots, n_{\mathrm{T}}-1\right), \\
& \mathbf{H}^{\mathrm{P}}(s) \mathbf{v}(s)=0
\end{aligned}
$$

In equation (6), $\lambda_{i}^{\mathrm{TP}}(s)$ is the potential-energy curvature in a direction of $\mathbf{L}_{i}^{\mathrm{TP}}(s)$, which is orthogonal to the IRP, and the corresponding vibrational frequency can be calculated in a unit of wave number as,

$$
v_{i}^{\mathrm{TP}}(s)=\frac{\sqrt{\lambda_{i}^{\mathrm{TP}}(s)}}{2 \pi c},
$$

where $c$ is the speed of light.

Using the basis vectors introduced above, nuclear positions can be represented by the reaction coordinate and $3 N-7$ normal coordinates, $\left\{s, Q_{1}, \ldots, Q_{3 N-7}\right\}$. For a given nuclear configuration $\mathbf{X}$ ( $=3 \mathrm{~N}$-dimensional mass-weighted Cartesian coordinates), one can define the closest point on the IRP (denoted as $\mathbf{X}^{\mathrm{IRP}}(s)$ ) in the initial step (simultaneously the reaction coordinate $s$ is determined). Then, normal coordinates can be determined by the following equations:

$$
\begin{aligned}
& Q_{\mathrm{T}, i}=\mathbf{L}_{i}^{\mathrm{TP}}(s)^{t}\left(\mathbf{X}-\mathbf{X}^{\mathrm{IRP}}(s)\right), \quad\left(i=1, \ldots, n_{\mathrm{T}}-1\right), \\
& Q_{\mathrm{N}, i}=\mathbf{L}_{i}^{\mathrm{N}}(s)^{t}\left(\mathbf{X}-\mathbf{X}^{\mathrm{IRP}}(s)\right), \quad\left(i=1, \ldots, n_{\mathrm{N}}\right) .
\end{aligned}
$$

By applying the reverse transformation, nuclear coordinates can be expressed as follows.

$$
\mathbf{X}=\mathbf{X}^{\mathrm{IRP}}(s)+\sum_{i=1}^{n_{\mathrm{T}}-1} Q_{\mathrm{T}, i} \mathbf{L}_{i}^{\mathrm{TP}}(s)+\sum_{i=1}^{n_{\mathrm{N}}} Q_{\mathrm{N}, i} \mathbf{L}_{i}^{\mathrm{N}}(s) .
$$

Under the harmonic approximation to directions orthogonal to the IRP, the potential energy for $\mathbf{X}$ can be written as,

$$
V(\mathbf{X})=V^{\mathrm{IRP}}(s)+\sum_{i=1}^{n_{\mathrm{T}}-1} \frac{1}{2} \lambda_{i}^{\mathrm{TP}}(s) Q_{\mathrm{T}, i}{ }^{2}+\sum_{i=1}^{n_{\mathrm{N}}} \frac{1}{2} \lambda_{i}^{\mathrm{N}}(s) Q_{\mathrm{N}, i}{ }^{2},
$$

where $V^{\mathrm{IRP}}(s)$ is the potential energy at $s$ on the IRP. Equation (12) gives a full-dimensional PES (named as a reaction-path PES) which can be utilized for reaction-path-based dynamics. When VRI occurs with respect to the non-totally symmetric coordinate, $Q_{N, 1}$, the corresponding curvature $\lambda_{1}^{\mathrm{N}}$ changes its sign from positive to negative at the VRI point, and if the ridge character continues until 
reaching the terminal point, this point corresponds to the second TS which connects two symmetrically equivalent product minima with the lower symmetry. As to this type of reaction path, there are a lot of example reactions, e.g., the Berry pseudorotation in $\mathrm{SiH}_{4} \mathrm{~F}^{-}$[17,21,24], $\mathrm{H}_{3} \mathrm{CO}$ $\rightarrow \mathrm{H}_{2} \mathrm{COH},[16,17,22,25]$, cyclopropylidene $\rightarrow$ allene $[10,11,17]$.

If a force constant of the totally-symmetric mode, e.g., $\lambda_{1}^{\mathrm{TP}}$, changes its sign from positive to negative somewhere on the IRP, this point may be classified as a totally-symmetric VRI point. In this case, the reaction-path tangent vector $\mathbf{v}(s)$ and the totally-symmetric normal mode vector $\mathbf{L}_{1}^{\mathrm{TP}}(s)$ can have a non-zero curvature coupling defined as [5],

$$
B_{1, s}=\left(\frac{d \mathbf{L}_{1}^{\mathrm{TP}}(s)}{d s}\right)^{t} \mathbf{v}(s)=-\left(\frac{d \mathbf{v}(s)}{d s}\right)^{t} \mathbf{L}_{1}^{\mathrm{TP}}(s) .
$$

Due to this curvature coupling, even if $\lambda_{1}^{\text {TP }}$ changes its sign from positive to negative at some point, it should become again a positive value through a ridge-valley inflection point along the IRP, and the IRP would reach a minimum. This consideration suggests that the totally-symmetric VRI possibly appears in many reactions, but it is difficult to notice them because the IRP calculation finishes at the minimum point on the PES. One of the present authors (TT) previously examined the isotope effect on the IRP which accompanies a non-totally-symmetric VRI point on the way and finishes at the first-order saddle point $[22,23]$. The molecular spatial symmetry can be easily reduced by an isotopic substitution in mass-weighted coordinates, and in the reduced symmetry, the non-totally-symmetric VRI can change to a totally-symmetric VRI. If the totally-symmetric VRI appears on the way of the IRP and the ridge character remains at the terminal stationary point, this terminal should be a transition state which connects two product minima of different type. When this type of reaction pathway is realized, however, the energy gradient must approach zero while the molecule stays on the ridge region along the IRP. As far as we know, there has been only one report about this type of reaction pathway, i.e., the IRP for a geometrical transformation in the water trimer [26].

In previous studies, a totally-symmetric VRI point was detected on the IRP for $\mathrm{HCHO}^{-}+$ $\mathrm{CH}_{3} \mathrm{Cl}$, and two channels leading to different product minima were found in calculations of reaction pathway with different conditions [27]. Taking this reaction and its analogous reaction, $\mathrm{CH}_{3} \mathrm{CHO}^{-}+\mathrm{CH}_{3} \mathrm{Cl}$, as examples, we perform detailed analyses of the IRP. The details will be described and discussed in a next section.

\section{ILLUSTRATIVE APPLICATIONS}

As illustrative applications, we examine an electron-transfer reaction, $\mathrm{XCHO}^{-}+\mathrm{CH}_{3} \mathrm{Cl}$, in which an electron is transferred from a ketyl radical anion to an alkyl halide [28]. Sastry and Shaik 
performed the steepest descent path calculation for the reaction, $\mathrm{HCHO}^{-}+\mathrm{CH}_{3} \mathrm{Cl}$, using non-mass-weighted internal coordinates and mass-weighted Cartesian coordinates at the spin-unrestricted Hartree-Fock (UHF) level, and noted that these calculations lead to different product minima, i.e., $\mathrm{HCHO}+\mathrm{CH}_{3}+\mathrm{Cl}^{-}$(the cluster of electron-transfer products: $\mathrm{C}_{\mathrm{ET}}$ ) and $\mathrm{OH}_{2} \mathrm{C}-\mathrm{CH}_{3}+\mathrm{Cl}^{-}$(the substitution: $\mathrm{SUB}(\mathrm{C})$ ), respectively [27,29]. This result suggests that the reaction pathway is very sensitive to the computational level and the pathway should go through the vicinity of the branching point of two different product minima. Yamataka, Aida, and Dupuis performed AIMD simulations for this reaction at the UHF level, and discussed the branching ratio of the products, $\mathrm{C}_{\mathrm{ET}}$ and $\mathrm{SUB}(\mathrm{C})$ [30]. Schlegel and coworkers also performed AIMD simulations considering the temperature effect on this reaction, and discussed the possibility of the stepwise process, $\mathrm{HCHO}^{-}+\mathrm{CH}_{3} \mathrm{Cl} \rightarrow \mathrm{C}_{\mathrm{ET}} \rightarrow \mathrm{SUB}(\mathrm{C})[31,32]$.

In this study, we performed geometry optimizations of stationary points and IRP calculations for the reactions $\mathrm{XCHO}^{-}+\mathrm{CH}_{3} \mathrm{Cl}\left(\mathrm{X}=\mathrm{H}, \mathrm{CH}_{3}\right)$ at the spin-unrestricted Møller-Plesset second-order perturbation theory (UMP2) level with $6-31+\mathrm{G}(\mathrm{d})$ basis sets. In IRP calculations, a step size of 0.1 bohr amu ${ }^{1 / 2}$ was employed. Then, we performed normal mode analyses at points along the IRP, according to equations (4) and (6). We also calculated changes of the Mulliken net charge and spin population of each atom, as well as the energy of the first-excited state, along the IRP. All calculations were performed using the GAMESS program package [33].

\section{III-A. $\mathrm{HCHO}^{-}+\mathrm{CH}_{3} \mathrm{Cl}$}

Figure 1 shows the scheme of electron transfer reactions between formaldehyde radical anion and methyl chloride. Initially these two molecules form a cluster (referred to as $C_{R}$ ), and then electron is transferred between these two molecules, leading to either one of two different product minima, $\mathrm{SUB}(\mathrm{C})$ or $\mathrm{C}_{\mathrm{ET}}$, via the transition state, ET-TS. There is another channel from $\mathrm{C}_{\mathrm{R}}$, which leads to $\mathrm{SUB}(\mathrm{O})$ via the transition state, $\mathrm{SUB}(\mathrm{O})$-TS. Two minima, $\mathrm{SUB}(\mathrm{C})$ and $\mathrm{C}_{\mathrm{ET}}$, are connected via the transition state, referred to as $\mathrm{R}_{\mathrm{AT}}-\mathrm{TS}$. The structure of ET-TS has $\mathrm{C}_{\mathrm{s}}$ symmetry in which $\mathrm{HCHO}$ approach $\mathrm{CH}_{3} \mathrm{Cl}$ with anti-conformation. The imaginary-frequency mode at this ET-TS belongs to A' representation, and so the molecular system keeps $\mathrm{C}_{\mathrm{s}}$ symmetry along the IRP. The structure with eclipse-conformation of $\mathrm{HCHO}$ and $\mathrm{CH}_{3} \mathrm{Cl}\left(\mathrm{C}_{\mathrm{s}}\right.$ symmetry $)$ has two imaginary-frequency modes (classified as the second-order saddle-point: SOSP) with the energy of $0.2 \mathrm{kcal} / \mathrm{mol}$ higher than ET-TS. One of two imaginary-frequency modes corresponds to atomic movement leading to $\mathrm{SUB}(\mathrm{C})$ or $\mathrm{C}_{\mathrm{ET}}$, while the other corresponds to an internal rotation of the $\mathrm{CH}_{3}$ group. The order in energy for the anti-conformation and the eclipse-conformation is changed if diffuse functions are not contained in the basis sets at the UMP2 level. This change was also observed in UHF calculations [29]. Through IRP calculations, it is verified that $C_{R}$ and $\operatorname{SUB}(C)$ are connected via ET-TS at the UMP2/6-31+G(d) level. The obtained $\mathrm{SUB}(\mathrm{C})$ has a $\mathrm{C}_{\mathrm{s}}$-symmetry 
structure with no imaginary-frequency mode, while there is another minimum-energy-structure of $\operatorname{SUB}(C)$ with $C_{1}$ symmetry, which is $1.2 \mathrm{kcal} / \mathrm{mol}$ lower than the $\mathrm{C}_{\mathrm{s}}$-symmetry structure. The difference in these $\mathrm{C}_{\mathrm{s}}$ and $\mathrm{C}_{1}$ structures are just the position of $\mathrm{Cl}^{-}$atom relative to $\mathrm{HCHOCH}_{3}$. The existence of these $C_{s}$ and $C_{1}$ minima indicates the possibility of appearance of the non-totally-symmetric VRI on the IRP of $\mathrm{C}_{\mathrm{s}}$ symmetry. It is found that $\mathrm{R}_{\mathrm{AT}}$-TS also has a $\mathrm{C}_{\mathrm{s}}$-symmetry structure with anti-conformation of $\mathrm{HCHO}-\mathrm{CH}_{3}$. Then, the IRP starting from this $\mathrm{R}_{\mathrm{AT}}$-TS keeps $\mathrm{C}_{\mathrm{s}}$ symmetry, leading to $\mathrm{C}_{\mathrm{ET}}$ and $\mathrm{SUB}(\mathrm{C})$ of $\mathrm{C}_{\mathrm{s}}$ symmetry.

Figure 2 shows variations of the energy along the IRPs for SUB(O) $\rightarrow \mathrm{SUB}(\mathrm{O})-\mathrm{TS} \rightarrow \mathrm{C}_{R}$ $\rightarrow$ ET-TS $\rightarrow \mathrm{SUB}(\mathrm{C}) \rightarrow \mathrm{R}_{\mathrm{AT}}$-TS $\rightarrow \mathrm{C}_{\mathrm{ET}}$ where the energy values are relative to a sum of energies of reactants, $\mathrm{HCHO}^{-}$and $\mathrm{CH}_{3} \mathrm{Cl}$. As shown in Fig. 2, $\mathrm{SUB}(\mathrm{C})$ is the lowest minimum-energy-structure, and $\mathrm{C}_{\mathrm{ET}}$ and $\mathrm{SUB}(\mathrm{O})$ are located with 5.0 and $2.9 \mathrm{kcal} / \mathrm{mol}$ higher than $\operatorname{SUB}(\mathrm{C})$, respectively. Starting from $\mathrm{C}_{\mathrm{R}}$, the activation barrier is calculated to be 7.1 and 8.8 $\mathrm{kcal} / \mathrm{mol}$ for $\mathrm{C}_{\mathrm{R}} \rightarrow \mathrm{SUB}(\mathrm{C})$ and $\mathrm{C}_{\mathrm{R}} \rightarrow \mathrm{SUB}(\mathrm{O})$, respectively. The value of $<\mathrm{S}^{2}>$ for ET-TS is 0.77 and rises to a maximum of 0.86 along the IRP at the UMP2 level, indicating that spin contamination does not cause significant distortion of the PES for this reaction. Figure 3 shows variations of (a) net charges of three fragments, i.e., $\mathrm{HCHO}, \mathrm{CH}_{3}$ and $\mathrm{Cl}$, and (b) spin population of elements other than $\mathrm{H}$ atoms along the IRP for $\mathrm{C}_{\mathrm{R}} \rightarrow \mathrm{ET}-\mathrm{TS} \rightarrow \mathrm{SUB}(\mathrm{C})$ in a region of $s=-10 \sim 15 \mathrm{bohr} \mathrm{amu}{ }^{1 / 2}$, obtained from Mulliken population analyses. Since this is an electron-transfer reaction between a radical anion and a neutral molecule, the sum of total charges is -1 . As is clearly shown in Fig. 3a, an electron is transferred from $\mathrm{HCHO}$ to $\mathrm{Cl}$ in the region slightly after ET-TS. On the other hand, variations of spin population indicate that an unpaired electron moves from the carbon in $\mathrm{HCHO}^{-}$to the oxygen in $\operatorname{SUB}(C)$ as the reaction proceeds.

Figure 4 shows variations of the lowest frequencies for three transverse vibrational modes, i.e., two totally-symmetric modes, $\mathbf{L}_{1}^{\mathrm{TP}}$ and $\mathbf{L}_{2}^{\mathrm{TP}}$, and one non-totally-symmetric mode, $\mathbf{L}_{1}^{\mathrm{N}}$, along the IRP for ET-TS $\rightarrow \mathrm{SUB}(\mathrm{C})$ in a region of $s=0 \sim 15 \mathrm{bohr} \mathrm{amu}{ }^{1 / 2}$, at the UMP2/6-31+G(d) level. As shown in Fig. 4, frequencies for $\mathbf{L}_{1}^{\mathrm{N}}$ and $\mathbf{L}_{1}^{\mathrm{TP}}$ modes become an imaginary number at $s$ $=5.82$ and $5.94 \mathrm{bohr} \mathrm{amu}^{1 / 2}$, respectively, although they become again a real number later. In the previous study on the same reaction, the totally-symmetric VRI occurs on the IRP just after passing the TS at the UHF level, and this VRI point is considered to be related to the branching of product minima [27]. As shown in Fig. 2, the potential energy at $s=5.82$ and $5.94 \mathrm{bohr} \mathrm{amu}^{1 / 2}$ is much lower than the energy level at $\mathrm{R}_{\mathrm{AT}}-\mathrm{TS}$, and thus, the VRI points in Fig. 4 have no relation with the branching to $\mathrm{SUB}(\mathrm{C})$ and $\mathrm{C}_{\mathrm{ET}}$. On the other hand, the frequency of $\mathbf{L}_{1}^{\mathrm{TP}}$ mode decreases sharply to $18.3 \mathrm{~cm}^{-1}$ at $s=0.8 \mathrm{bohr} \mathrm{amu}^{1 / 2}$ where the potential energy is sufficiently higher than the energy level of $\mathrm{R}_{\mathrm{AT}}$-TS. Figure 5 shows pictures of significant normal modes, $\mathbf{L}_{1}^{\mathrm{TP}}(s=0.8), \mathbf{L}_{1}^{\mathrm{TP}}(s=$ $6.0)$, and $\mathbf{L}_{1}^{\mathrm{N}}(s=6.0)$, and the reaction-path tangent vector, $\mathbf{v}(s=0.8)$. At $s=0.8$ bohr amu ${ }^{1 / 2}, \mathbf{v}$ corresponds to atomic motions promoting a cleavage of the $\mathrm{C}-\mathrm{Cl}$ bond in $\mathrm{CH}_{3} \mathrm{Cl}$ and a formation of the $\mathrm{C}-\mathrm{C}$ bond between $\mathrm{HCHO}$ and $\mathrm{CH}_{3} \mathrm{Cl}$ (namely, $\mathrm{SUB}(\mathrm{C})$ ), while $\mathbf{L}_{1}^{\mathrm{TP}}$ corresponds to atomic 
motions leading to dissociation into three fragments, $\mathrm{HCHO}, \mathrm{CH}_{3}$, and $\mathrm{Cl}$ (namely, $\mathrm{C}_{\mathrm{ET}}$ ). The low frequency means a low potential-curvature (i.e., a small force constant), indicating that the molecular system possibly leaves from the IRP through vibrational excitation of this low-frequency-mode and goes toward another product minimum, $\mathrm{C}_{\mathrm{ET}}$.

In order to get insights to geometrical feature of the IRP for ET-TS $\rightarrow$ SUB(C) around the low-frequency region, we calculated the reaction-path curvature by numerical differentiation of the reaction-path tangent vectors in the region of $s=0 \sim 5 \mathrm{bohr} \mathrm{amu}^{1 / 2}$. Figure 6 shows variations of the reaction-path curvature along the IRP. As shown in Fig. 6, the IRP is sharply curved locally at $s$ $=0.7 \sim 1.2 \mathrm{bohr} \mathrm{amu}^{1 / 2}$. In this region, the reaction-path tangent vector changes its direction following three stages:

1. $\mathrm{CH}_{3}$ part in $\mathrm{CH}_{3} \mathrm{Cl}$ approaches to the planar structure $\left(s=0.0 \sim 0.7\right.$ bohr amu $\left.{ }^{1 / 2}\right)$

2. The planar $\mathrm{CH}_{3}$ is transferred from $\mathrm{Cl}$ to the $\mathrm{HCHO}$ side $\left(s=0.7 \sim 1.2 \mathrm{bohr} \mathrm{amu}^{1 / 2}\right)$

3. $\mathrm{CH}_{3}$ part changes again to non-planar structure to make $\mathrm{OH}_{2} \mathrm{C}-\mathrm{CH}_{3}\left(s=1.2 \sim 5.5 \mathrm{bohr} \mathrm{amu}^{1 / 2}\right)$

During these processes, the hybrid orbital of $\mathrm{C}$ atom in $\mathrm{CH}_{3}$ should change as $\mathrm{sp}^{3} \rightarrow \mathrm{sp}^{2} \rightarrow \mathrm{sp}^{3}$. This picture is consistent with the recoil mechanism proposed by Shaik et al., in which two hydrogen atoms of the $\mathrm{H}_{2} \mathrm{CO}$ fragment flap against the methyl group in opposition to the $\mathrm{C}-\mathrm{C}$ approach, and thus the $\mathrm{C}-\mathrm{C}$ bond does not change as much but the $\mathrm{C}-\mathrm{Cl}$ bond lengthens more rapidly [27]. The geometrical feature of the reaction-path tangent vector also appears as characteristic variations in net charges and spin populations at $s=0.8 \sim 1.5 \mathrm{bohr} \mathrm{amu}^{1 / 2}$ (see Fig. 3). In the second step, vibrational frequency of the transverse normal mode leading to dissociations into $\mathrm{HCHO}+\mathrm{CH}_{3}+$ $\mathrm{Cl}^{-}$decreases rapidly, and the branching channel should be open.

In the previous study for reactions of $\mathrm{H}_{2} \mathrm{CS} \rightarrow \mathrm{HCSH}$ and $\mathrm{H}_{2} \mathrm{CS} \rightarrow \mathrm{H}_{2}+\mathrm{CS}$ [18-20], the appearance of non-totally-symmetric VRI points along the IRP was explained by the second-order Jahn-Teller (SOJT) theory in which the non-totally-symmetric electronic excited state mixes with the totally symmetric electronic ground state through geometrical deformation in a direction of the non-totally-symmetric normal coordinate when these two electronic states approach each other in energy (vibronic interaction). This interaction sometimes invokes a change of geometrical feature of points on the IRP from the bottom of valley to the top of ridge. In the present case, the IRP for $\mathrm{C}_{\mathrm{R}} \rightarrow$ ET-TS $\rightarrow \mathrm{SUB}(\mathrm{C})$ keeps $\mathrm{C}_{\mathrm{s}}$ symmetry throughout, and the electronic ground state belongs to $\mathrm{A}^{\prime}$ irreducible representation. Figure 7 shows variations of the ground-state $\left(1^{2} \mathrm{~A}^{\prime}\right)$ and excited-state $\left(1^{2} \mathrm{~A}^{\prime}\right)$ potential energies along the IRP calculated by the UMP2/6-31+G(d) method. As shown in Fig. 7, the excited state approaches rapidly the ground state with the energy difference of $4.8 \mathrm{kcal} / \mathrm{mol}$ at $s=5.7 \mathrm{bohr} \mathrm{amu}^{1 / 2}$, and their small energy difference is kept after this region (the energy difference in the terminal is calculated to be $3.6 \mathrm{kcal} / \mathrm{mol}$ ). This feature indicates that the energy of the first-excited state is very close to that of the ground state in the product, $\mathrm{OH}_{2} \mathrm{C}-\mathrm{CH}_{3}$. Also, according to the SOJT theory, the non-totally-symmetric VRI around $s=5.82 \mathrm{bohr} \mathrm{amu}^{1 / 2}$ should be invoked by the vibronic interaction between $1^{2} \mathrm{~A}^{\prime}$ and $1^{2} \mathrm{~A}^{\prime \prime}$ states, which may be related to 
the branching of $\mathrm{C}_{\mathrm{s}}$ and $\mathrm{C}_{1}$ minima of $\mathrm{SUB}(\mathrm{C})$. As to the totally-symmetric VRI points, however, the mechanism of its appearance could not be explained by the SOJT theory because the interaction of the ground and first excited states of totally-symmetric representation is not forbidden at points on the IRP [18-20].

\section{III-B. $\mathrm{CH}_{3} \mathrm{CHO}^{-}+\mathrm{CH}_{3} \mathrm{Cl}$}

The IRP analyses were also performed for an electron transfer reaction between acetaldehyde radical anion and methyl chloride $\left(\mathrm{CH}_{3} \mathrm{CHO}^{-}+\mathrm{CH}_{3} \mathrm{Cl}\right)$, the scheme of which is shown in Fig. 8. In this reaction one of $\mathrm{H}$ atoms of $\mathrm{HCHO}^{-}$in the previous reaction is just substituted with a $\mathrm{CH}_{3}$ group, which results in $\mathrm{C}_{1}$ symmetry of the total system. The reaction scheme is almost similar to that in $\mathrm{HCHO}^{-}+\mathrm{CH}_{3} \mathrm{Cl}$, which contains three elementary reactions, $\mathrm{C}_{\mathrm{R}} \rightarrow$ ET-TS $\rightarrow$ $\mathrm{SUB}(\mathrm{C}), \mathrm{C}_{\mathrm{R}} \rightarrow \mathrm{SUB}(\mathrm{O})-\mathrm{TS} \rightarrow \mathrm{SUB}(\mathrm{O})$, and $\mathrm{SUB}(\mathrm{C}) \rightarrow \mathrm{R}_{\mathrm{AT}}-\mathrm{TS} \rightarrow \mathrm{C}_{\mathrm{ET}}$. All the structures along the IRPs have no spatial symmetry (i.e., $\mathrm{C}_{1}$ symmetry). In the structure of ET-TS, $\mathrm{CH}_{3} \mathrm{CHO}$ approach $\mathrm{CH}_{3} \mathrm{Cl}$ with anti-conformation and the imaginary-frequency mode indicates that the central $\mathrm{CH}_{3}$ group moves from $\mathrm{Cl}$ to $\mathrm{CH}_{3} \mathrm{CHO}$ part. The structure with eclipse-conformation of $\mathrm{CH}_{3} \mathrm{CHO}$ and $\mathrm{CH}_{3} \mathrm{Cl}$ could not be found. The IRP calculations show that $\mathrm{C}_{\mathrm{R}}$ and $\mathrm{SUB}(\mathrm{C})$ are connected via ET-TS at the UMP2/6-31+G(d) level. The obtained structure for $\operatorname{SUB}(\mathrm{C})$ corresponds to the minimum, while there is another minimum-energy-structure of $\mathrm{SUB}(\mathrm{C})$, which is $0.2 \mathrm{kcal} / \mathrm{mol}$ lower than the terminal of the IRP. The difference in these structures are just the position of $\mathrm{Cl}^{-}$atom relative to $\mathrm{OCH}_{3} \mathrm{HC}-\mathrm{CH}_{3}$, which is analogous to $\mathrm{C}_{\mathrm{s}}$ and $\mathrm{C}_{1}$ structures of $\mathrm{SUB}(\mathrm{C})$ for $\mathrm{Cl}^{-} \ldots \mathrm{OH}_{2} \mathrm{C}-\mathrm{CH}_{3}$. Figure 9 shows variations of the energy along the IRPs for $\mathrm{SUB}(\mathrm{O}) \rightarrow \mathrm{SUB}(\mathrm{O})-\mathrm{TS} \rightarrow \mathrm{C}_{\mathrm{R}} \rightarrow$ ET-TS $\rightarrow \mathrm{SUB}(\mathrm{C}) \rightarrow \mathrm{R}_{\mathrm{AT}}-\mathrm{TS} \rightarrow \mathrm{C}_{\mathrm{ET}}$ where the energy values are relative to a sum of energies of reactants, $\mathrm{CH}_{3} \mathrm{CHO}^{-}$and $\mathrm{CH}_{3} \mathrm{Cl}$. The relation in energetics is similar to that in the previous reaction of $\mathrm{HCHO}^{-}+\mathrm{CH}_{3} \mathrm{Cl}$ : $\mathrm{SUB}(\mathrm{C})$ is the lowest minimum-energy-structure, and $\mathrm{C}_{\mathrm{ET}}$ and $\mathrm{SUB}(\mathrm{O})$ are located with 1.8 and $4.7 \mathrm{kcal} / \mathrm{mol}$ higher than $\mathrm{SUB}(\mathrm{C})$, respectively. Starting from $\mathrm{C}_{R}$, the activation barrier is calculated to be 4.6 and $8.7 \mathrm{kcal} / \mathrm{mol}$ for $\mathrm{C}_{R} \rightarrow \mathrm{SUB}(\mathrm{C})$ and $\mathrm{C}_{R} \rightarrow \mathrm{SUB}(\mathrm{O})$, respectively. The values of $\left\langle\mathrm{S}^{2}>\right.$ for ET-TS is 0.77 and rises to a maximum of 0.86 along the IRP, which are the same as the reaction of $\mathrm{HCHO}^{-}+\mathrm{CH}_{3} \mathrm{Cl}$. Figure 10 shows variations of (a) net charges of three fragments, i.e., $\mathrm{CH}_{3} \mathrm{CHO}, \mathrm{CH}_{3}$ and $\mathrm{Cl}$, and (b) spin population of elements other than $\mathrm{H}$ atoms along the IRP for $\mathrm{C}_{\mathrm{R}} \rightarrow$ ET-TS $\rightarrow \mathrm{SUB}(\mathrm{C})$ in a region of $s=-10 \sim 15 \mathrm{bohr} \mathrm{amu} u^{1 / 2}$, obtained from Mulliken population analyses. As shown in Fig. 10a, an electron is transferred from $\mathrm{CH}_{3} \mathrm{CHO}$ to $\mathrm{Cl}$ in the region slightly after ET-TS. Figure $10 \mathrm{~b}$ indicates that a position of an unpaired electron moves from the carbon in $\mathrm{CH}_{3} \mathrm{CHO}^{-}$to the oxygen in $\mathrm{SUB}(\mathrm{C})$ along the IRP.

Figure 11 shows variations of frequencies for three transverse vibrational modes, $\mathbf{L}_{1}^{\mathrm{TP}}$, $\mathbf{L}_{2}^{\mathrm{TP}}$, and $\mathbf{L}_{3}^{\mathrm{TP}}$ along the IRP for ET-TS $\rightarrow \mathrm{SUB}(\mathrm{C})$ in a region of $s=0 \sim 15 \mathrm{bohr} \mathrm{amu}^{1 / 2}$, at the 
UMP2 $/ 6-31+G(d)$ level. Since the molecular system has no spatial symmetry, these three modes are all totally-symmetric-modes of A irreducible representation. Variations of frequencies in Fig. 11 show analogous features with those in Fig. 4. The frequency for $\mathbf{L}_{1}^{\mathrm{TP}}$ shows a rapid decrease and becomes an imaginary number at $s=0.75 \sim 1.03 \mathrm{bohr} \mathrm{amu}^{1 / 2}$, although in the previous $\mathrm{HCHO}^{-}$ $+\mathrm{CH}_{3} \mathrm{Cl}$ reaction the frequency keeps a real number in this region. Also, the frequencies for $\mathbf{L}_{1}^{\mathrm{TP}}$ and $\mathbf{L}_{2}^{\mathrm{TP}}$ become imaginary number at $s=6.03$ and $6.16 \mathrm{bohr} a \mathrm{amu}^{1 / 2}$, respectively, and become again a real number later. As shown in Fig. 9, the potential energy at $s=0.75 \mathrm{bohr} \mathrm{amu}^{1 / 2}$ is sufficiently higher than the energy level of $\mathrm{R}_{\mathrm{AT}} \mathrm{TS}$, and therefore, the first totally-symmetric VRI just after passing the TS should play a significant role in the branching of the products. Figure 12 shows pictures of significant normal modes, $\mathbf{L}_{1}^{\mathrm{TP}}(s=0.9), \mathbf{L}_{1}^{\mathrm{TP}}(s=7.0)$, and $\mathbf{L}_{2}^{\mathrm{TP}}(s=7.0)$, and the reaction-path tangent vector, $\mathbf{v}(s=0.9)$. At $s=0.9 \mathrm{bohr} \mathrm{amu}^{1 / 2}, \mathbf{v}$ corresponds to atomic motions promoting a cleavage of the $\mathrm{C}-\mathrm{Cl}$ bond in $\mathrm{CH}_{3} \mathrm{Cl}$ and a formation of the $\mathrm{C}-\mathrm{C}$ bond between $\mathrm{CH}_{3} \mathrm{CHO}$ and $\mathrm{CH}_{3} \mathrm{Cl}$, while $\mathbf{L}_{1}^{\mathrm{TP}}$ corresponds to atomic motions leading to dissociation into three fragments, $\mathrm{CH}_{3} \mathrm{CHO}, \mathrm{CH}_{3}$, and $\mathrm{Cl}$. In the ridge region related to $\mathbf{L}_{1}^{\mathrm{TP}}$ at $s=0.75 \sim 1.03 \mathrm{bohr}$ $\mathrm{amu}^{1 / 2}$, the molecular system can leave from the IRP due to the instability of the reaction coordinate, and can go toward another product minimum, $\mathrm{C}_{\mathrm{ET}}$.

Figure 13 shows variations of the reaction-path curvature along the IRP for ET-TS $\rightarrow$ $\operatorname{SUB}(\mathrm{C})$ in the region of $s=0 \sim 5 \mathrm{bohr} \mathrm{amu}^{1 / 2}$. The IRP is sharply curved locally at $s=0.7 \sim 1.4$ bohr $\mathrm{amu}^{1 / 2}$. In this region, the reaction-path tangent vector changes its direction in the same way as that for $\mathrm{HCHO}^{-}+\mathrm{CH}_{3} \mathrm{Cl}$, in which $\mathrm{CH}_{3}$ part in $\mathrm{CH}_{3} \mathrm{Cl}$ approaches to the planar structure, the planar $\mathrm{CH}_{3}$ is transferred from $\mathrm{Cl}$ to the $\mathrm{CH}_{3} \mathrm{CHO}$ side, and $\mathrm{CH}_{3}$ part changes again to non-planar structure to make the molecule $\mathrm{CH}_{3} \mathrm{CHO}-\mathrm{CH}_{3}$. Simultaneously, the hybrid orbital of $\mathrm{C}$ atom in $\mathrm{CH}_{3}$ changes as $\mathrm{sp}^{3} \rightarrow \mathrm{sp}^{2} \rightarrow \mathrm{sp}^{3}$. In the above second step, the branching channel to $\mathrm{CH}_{3} \mathrm{CHO}+$ $\mathrm{CH}_{3}+\mathrm{Cl}^{-}$will be open through the totally-symmetric VRI point. Mulliken charges and spin populations also show characteristic variations around this region in Fig. 10.

As is described above, the reaction system has no spatial symmetry along the IRP for $\mathrm{CH}_{3} \mathrm{CHO}^{-}+\mathrm{CH}_{3} \mathrm{Cl}$, so the electronic states as well as molecular orbitals belong to A irreducible representation. In general, it is difficult to get the converged result for the excited state in $\mathrm{C}_{1}$ symmetry by the UHF method, but we fortunately got the converged result for $2^{2} \mathrm{~A}$ state along the IRP by preparing a set of initial orbitals for SCF calculations in which SOMO and the second-HOMO in the ground state are changed. Figure 14 shows variations of the ground-state $\left(1^{2} \mathrm{~A}\right)$ and the first-excited-state $\left(2^{2} \mathrm{~A}\right)$ potential energies along the IRP calculated by the UMP2/6-31+G(d) method. As shown in Fig. 14, the excited state approaches rapidly the ground state with the energy difference of $6.5 \mathrm{kcal} / \mathrm{mol}$ at $s=6.1 \mathrm{bohr} \mathrm{amu}^{1 / 2}$, and their small energy difference is kept after this region (the energy difference in the terminal is calculated to be 4.2 $\mathrm{kcal} / \mathrm{mol}$ ). Thus, the energy of the first-excited state is very close to that of the ground state in the product, $\mathrm{OCH}_{3} \mathrm{HC}-\mathrm{OCH}_{3}$. 
In the previous section, appearance of the non-totally-symmetric VRI point was explained by the SOJT theory, and simultaneously we pointed out the difficulty to understand appearance of the totally-symmetric VRI points based on the vibronic interaction between the ground and the first-excited state. Actually it is difficult to explain the appearance of the totally-symmetric VRI point at $s=0.75 \mathrm{bohr} \mathrm{amu}^{1 / 2}$ in the present reaction by the SOJT theory, but the totally-symmetric VRI point at $s=6.03 \mathrm{bohr} \mathrm{amu}^{1 / 2}$ could be understood as the result of the vibronic interaction between $1^{2} \mathrm{~A}$ and $2^{2} \mathrm{~A}$ electronic states (this VRI point may be related to the branching of two minima of $\operatorname{SUB}(C)$ ). We should note that the present molecular system has approximately $\mathrm{C}_{\mathrm{s}}$ symmetry because only one of $\mathrm{H}$ atoms is substituted with $\mathrm{CH}_{3}$ group in the $\mathrm{C}_{\mathrm{s}}$-symmetry molecular system. In such a case, one may apply the SOJT theory approximately to interpret appearance of the totally symmetric VRI points on the IRP.

\section{CONCLUSION}

In the present paper, we discuss the significant role of the totally-symmetric VRI points appearing on the IRP. Since the intrinsic reaction coordinate belongs to the totally-symmetric irreducible representation of the molecular point group, it has no curvature coupling with the transverse normal coordinates of non-total-symmetry, and thus the IRP starting from TS is sometimes connected with the second TS through the non-totally-symmetric VRI point. This type of VRI points were sufficiently studied since it is easy to find such cases in quantum chemical calculations. On the other hand, the totally-symmetric normal coordinates definitely have a curvature coupling with the reaction coordinate, and thus, even if the totally-symmetric VRI point appears on the way of the IRP, the valley character is usually recovered through the ridge-valley inflection point, leading to the product minimum. Therefore it is difficult to find the totally-symmetric VRI points. When there appears the totally-symmetric VRI point on the IRP, the molecular system with non-zero kinetic energy will possibly turn its direction on the way, and sometimes reach another minimum on the PES.

We show illustrative quantum-chemical calculations of the IRP for electron-transfer reactions, $\mathrm{XCHO}^{-}+\mathrm{CH}_{3} \mathrm{Cl}\left(\mathrm{X}=\mathrm{H}, \mathrm{CH}_{3}\right)$, at the $\mathrm{UMP} 2 / 6-31+\mathrm{G}(\mathrm{d})$ level. There are two channels in the products, i.e., OXHC- $\mathrm{CH}_{3}+\mathrm{Cl}^{-}$and $\mathrm{XCHO}+\mathrm{CH}_{3}+\mathrm{Cl}^{-}$, in these reactions. Variations of vibrational frequency of the transverse modes, the reaction-path curvature, Mulliken charges of molecular fragments, and atomic spin populations were calculated along the IRP. It was known that there is a totally-symmetric VRI point on the IRP for the first reaction $(X=H)$ at the UHF level, but it is verified that this VRI point disappears at the UMP2 level. On the other hand, in the second reaction $\left(\mathrm{X}=\mathrm{CH}_{3}\right)$, it is verified that the IRP has the totally-symmetric VRI point leading to two different product minima on the PES even at the UMP2 level.

The appearance mechanism of the VRI point was discussed by the SOJT theory. The 
energy of the first-excited state is calculated along the IRP, and it is shown that the non-totally-symmetric VRI point appears as the result of the vibronic interaction between the ground and the excited states. On the other hand, appearance of the totally-symmetric VRI point could not be explained by the SOJT theory, in general. However, in the present application for $\mathrm{CH}_{3} \mathrm{CHO}^{-}+$ $\mathrm{CH}_{3} \mathrm{Cl}$, one totally-symmetric VRI point seems to be invoked by the vibronic interaction of $1^{2} \mathrm{~A}$ and $2^{2} \mathrm{~A}$ states, since the reaction system has approximately $\mathrm{C}_{\mathrm{s}}$ symmetry along the IRP.

In general, plural sets of products are generated simultaneously in the complex reaction, while only one set of products is generated in the elementary reaction. However, even in the elementary reaction, two different sets of products could be generated if there appear the totally-symmetric VRI points (or the region with the very low frequency in transverse modes) on the way of the IRP. Although the branching of products can be discussed only by dynamics simulations, one can expect different product channels from the vibrational analyses along the IRP.

\section{ACKNOWLEDGMENTS}

This paper is dedicated to Prof Shigeru Nagase on the occasion of his 65th birthday. This work was supported by a Grant-in-Aid for Scientific Research from the Ministry of Education, Culture, Sports, Science and Technology. The computations were performed using the Research Center for Computational Science, Okazaki, Japan. Y.H. thanks a support from GCOE program in Hokkaido University. 


\section{REFERENCES}

1. Born M, Oppenheimer JR (1927) Annalen der Physik 84:457-484

2. Fukui K (1970) J Phys Chem 74:4161

3. Truhlar DG, Garrett BC (1980) Acc Chem Res 13:440-448

4. Truhlar DG, Steckler R, Gordon MS (1987) Chem Rev 87:217-236

5. Miller WH, Handy NC, Adams JE (1980) J Chem Phys 72:99-112

6. Kato S, Morokuma K (1980) J Chem Phys 73:3900-3914

7. Taketsugu T, Gordon MS (1995) J Chem Phys 103:10042-10049

8. Taketsugu T, Gordon MS (1996) J Chem Phys 104:2834-2840

9. Taketsugu T, Hirao K (1997) J Chem Phys 107:10506-10514

10. Valtazanos P, Ruedenberg K (1986) Theor Chim Acta 69:281-307

11. Valtazanos P, Elbert ST, Xantheas S, Ruedenberg K (1991) Theor Chim Acta 78:287-326

12. Metiu H, Ross J, Silbey R, George TF (1974) J Chem Phys 61:3200.

13. Tachibana A, Okazaki I, Koizumi M, Hori K, Yamabe T (1985) J Am Chem Soc 107:1190-1196

14. Quapp W (1989) Theor Chim Acta 75:447-460

15. Schlegel HB (1994) J Chem Soc-Faraday Trans 90:1569-1574

16. Taketsugu T, Tajima N, Hirao K (1996) J Chem Phys 105:1933-1939

17. Yanai T, Taketsugu T, Hirao K (1997) J Chem Phys 107:1137-1146

18. Taketsugu T, Hirano T (1993) J Chem Phys 99:9806-9814

19. Taketsugu T, Hirano T (1994) J Mol Struct (THEOCHEM) 116:169-176

20. Taketsugu T, Hirao K (1999) In: Fueno T (ed) The Transition State: A Theoretical Approach. Kodansha-Gordon and Breach Science, pp 45-63

21. Taketsugu T, Yanai T, Hirao K, Gordon MS (1998) J Mol Struct (THEOCHEM) 451:163-177

22. Taketsugu T, Kumeda Y (2001) J Chem Phys 114:6973-6982

23. Kumeda Y, Taketsugu T (2000) J Chem Phys 113:477-484

24. Windus TL, Gordon MS, Burggraf LW, Davis LP (1991) J Am Chem Soc 113:4356-4357

25. Colwell SM, Handy NC (1985) J Chem Phys 82:1281-1290

26. Taketsugu T, Wales DJ (2002) Mol Phys 100:2793-2806.

27. Shaik S, Danovich D, Sastry GN, Ayala PY, Schlegel HB (1997) J Am Chem Soc 119:9237-9245

28. Zipse H (1997) Angewandte Chemie-International Edition in English 36:1697-1700

29. Sastry GN, Shaik S (1996) J Phys Chem 100:12241-12252

30. Yamataka H, Aida M, Dupuis M (1999) Chem Phys Let 300:583-587

31. Li J, Li XS, Shaik S, Schlegel HB (2004) J Phys Chem A 108:8526-8532

32. Lie J, Shaik S, Schlegel HB (2006) J Phys Chem A 110:2801-2806

33. Schmidt MW, Baldridge KK, Boatz JA, Elbert ST, Gordon MS, Jensen JH, Koseki S, Matsunaga N, Nguyen KA, Su SJ, Windus TL, Dupuis M, Montgomery JA (1993) J Comput Chem 14:1347-1363 


\section{FIGURE CAPTION}

Fig. 1. A schematic reaction profile for $\mathrm{HCHO}^{-}+\mathrm{CH}_{3} \mathrm{Cl}$.

Fig. 2. Energy variations along the IRP for three elementary reactions, $\operatorname{SUB}(\mathrm{O}) \rightarrow \mathrm{C}_{R}, \mathrm{C}_{\mathrm{R}} \rightarrow$ $\mathrm{SUB}(\mathrm{C})$, and $\mathrm{SUB}(\mathrm{C}) \rightarrow \mathrm{C}_{\mathrm{ET}}$, calculated for $\mathrm{HCHO}^{-}+\mathrm{CH}_{3} \mathrm{Cl}$ at the $\mathrm{UMP} 2 / 6-31+\mathrm{G}(\mathrm{d})$ level.

Fig. 3. Variations of (a) net charges of $\mathrm{HCHO}, \mathrm{CH}_{3}$, and $\mathrm{Cl}$ fragments and (b) spin population of elements other than $\mathrm{H}$ atoms along the IRP for $\mathrm{C}_{\mathrm{R}} \rightarrow$ ET-TS $\rightarrow \mathrm{SUB}(\mathrm{C})\left(\mathrm{HCHO}^{-}+\mathrm{CH}_{3} \mathrm{Cl}\right)$, obtained from Mulliken population analyses. $\mathrm{C}_{\mathrm{a}}$ denotes a carbon atom in $\mathrm{HCHO}^{-}$while $\mathrm{C}_{\mathrm{b}}$ denotes a carbon atom in $\mathrm{CH}_{3} \mathrm{Cl}$.

Fig. 4. Variations of projected frequencies of transverse normal modes with the low frequency along the IRP for ET-TS $\rightarrow \mathrm{SUB}(\mathrm{C})\left(\mathrm{HCHO}^{-}+\mathrm{CH}_{3} \mathrm{Cl}\right)$.

Fig. 5. Normal mode vectors and a reaction-path tangent vector at selected points on the IRP for $\mathrm{ET}-\mathrm{TS} \rightarrow \mathrm{SUB}(\mathrm{C})\left(\mathrm{HCHO}^{-}+\mathrm{CH}_{3} \mathrm{Cl}\right)$.

Fig. 6. Variations of the reaction-path curvature along the IRP for ET-TS $\rightarrow \mathrm{SUB}(\mathrm{C})\left(\mathrm{HCHO}^{-}+\right.$ $\mathrm{CH}_{3} \mathrm{Cl} ; s=0.0 \sim 5.0 \mathrm{bohr} \mathrm{amu}^{1 / 2}$ ).

Fig. 7. Variations of energies of the ground state $\left({ }^{2} \mathrm{~A}^{\prime}\right)$ and excited state $\left({ }^{2} \mathrm{~A}^{\prime \prime}\right)$ along the IRP for $\mathrm{ET}-\mathrm{TS} \rightarrow \mathrm{SUB}(\mathrm{C})\left(\mathrm{HCHO}^{-}+\mathrm{CH}_{3} \mathrm{Cl}\right)$ at the UMP2/6-31+G(d) level.

Fig. 8. A schematic reaction profile for $\mathrm{CH}_{3} \mathrm{CHO}^{-}+\mathrm{CH}_{3} \mathrm{Cl}$.

Fig. 9. Energy variations along the IRP for three elementary reactions, $\operatorname{SUB}(\mathrm{O}) \rightarrow \mathrm{C}_{R}, \mathrm{C}_{R} \rightarrow$ $\mathrm{SUB}(\mathrm{C})$, and $\mathrm{SUB}(\mathrm{C}) \rightarrow \mathrm{C}_{\mathrm{ET}}$, calculated for $\mathrm{CH}_{3} \mathrm{CHO}^{-}+\mathrm{CH}_{3} \mathrm{Cl}$ at the UMP2/6-31+G(d) level.

Fig. 10. Variations of (a) net charges of $\mathrm{CH}_{3} \mathrm{CHO}, \mathrm{CH}_{3}$, and $\mathrm{Cl}$ fragments and (b) spin population of elements other than $\mathrm{H}$ atoms along the IRP for $\mathrm{C}_{\mathrm{R}} \rightarrow$ ET-TS $\rightarrow \mathrm{SUB}(\mathrm{C})\left(\mathrm{CH}_{3} \mathrm{CHO}^{-}+\mathrm{CH}_{3} \mathrm{Cl}\right)$, obtained from Mulliken population analyses. $\mathrm{C}_{\mathrm{a}}$ and $\mathrm{C}_{\mathrm{c}}$ denote carbon atoms in $\mathrm{CH}_{3} \mathrm{CHO}^{-}\left(\mathrm{C}_{\mathrm{c}}\right.$ is a carbon atom of $\mathrm{CH}_{3}$ group) while $\mathrm{C}_{\mathrm{b}}$ denotes a carbon atom in $\mathrm{CH}_{3} \mathrm{Cl}$.

Fig. 11. Variations of projected frequencies of transverse normal modes with the low frequency along the IRP for ET-TS $\rightarrow \mathrm{SUB}(\mathrm{C})\left(\mathrm{CH}_{3} \mathrm{CHO}^{-}+\mathrm{CH}_{3} \mathrm{Cl}\right)$.

Fig. 12. Normal mode vectors and a reaction-path tangent vector at selected points on the IRP for $\mathrm{ET}-\mathrm{TS} \rightarrow \mathrm{SUB}(\mathrm{C})\left(\mathrm{CH}_{3} \mathrm{CHO}^{-}+\mathrm{CH}_{3} \mathrm{Cl}\right)$.

Fig. 13. Variations of the reaction-path curvature along the IRP for ET-TS $\rightarrow \mathrm{SUB}(\mathrm{C})\left(\mathrm{CH}_{3} \mathrm{CHO}^{-}+\right.$ $\mathrm{CH}_{3} \mathrm{Cl} ; s=0.0 \sim 5.0 \mathrm{bohr} \mathrm{amu}^{1 / 2}$ ).

Fig. 14. Variations of energies of the ground state $\left(1^{2} \mathrm{~A}\right)$ and excited state $\left(2^{2} \mathrm{~A}\right)$ along the IRP for $\mathrm{ET}-\mathrm{TS} \rightarrow \mathrm{SUB}(\mathrm{C})\left(\mathrm{CH}_{3} \mathrm{CHO}^{-}+\mathrm{CH}_{3} \mathrm{Cl}\right)$ at the $\mathrm{UMP} 2 / 6-31+\mathrm{G}(\mathrm{d})$ level. 


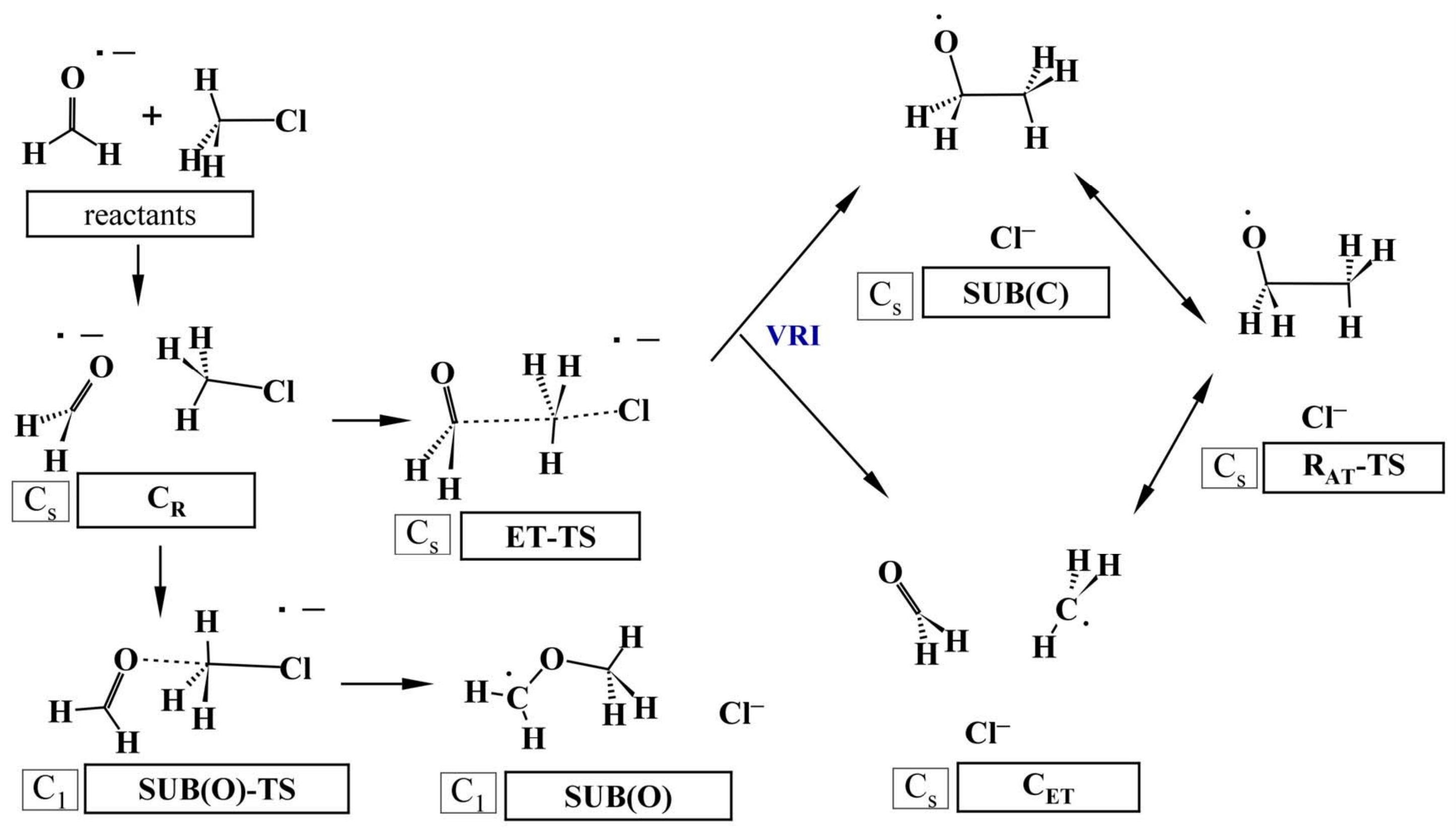


Figure 2

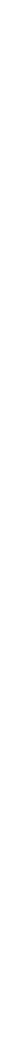




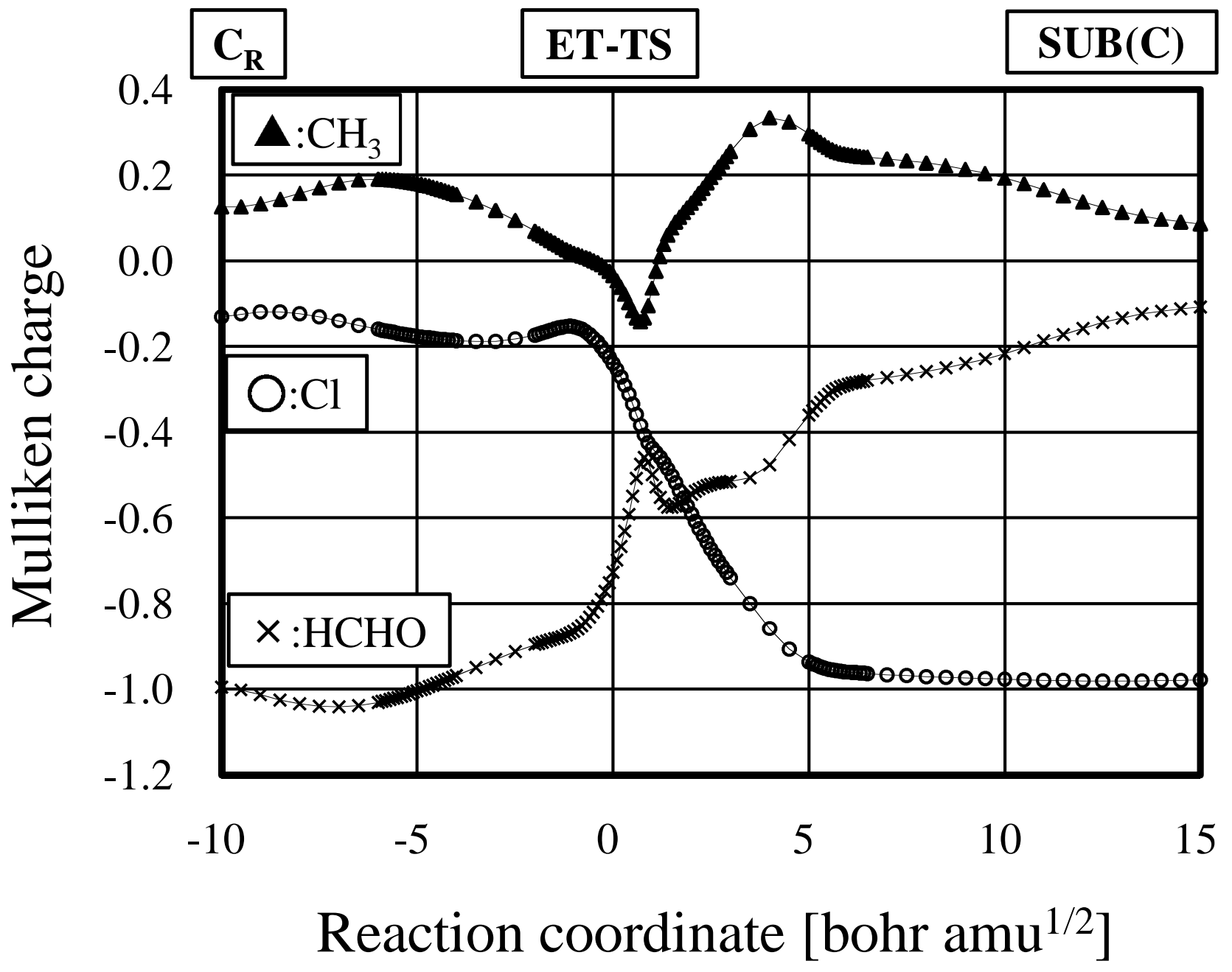




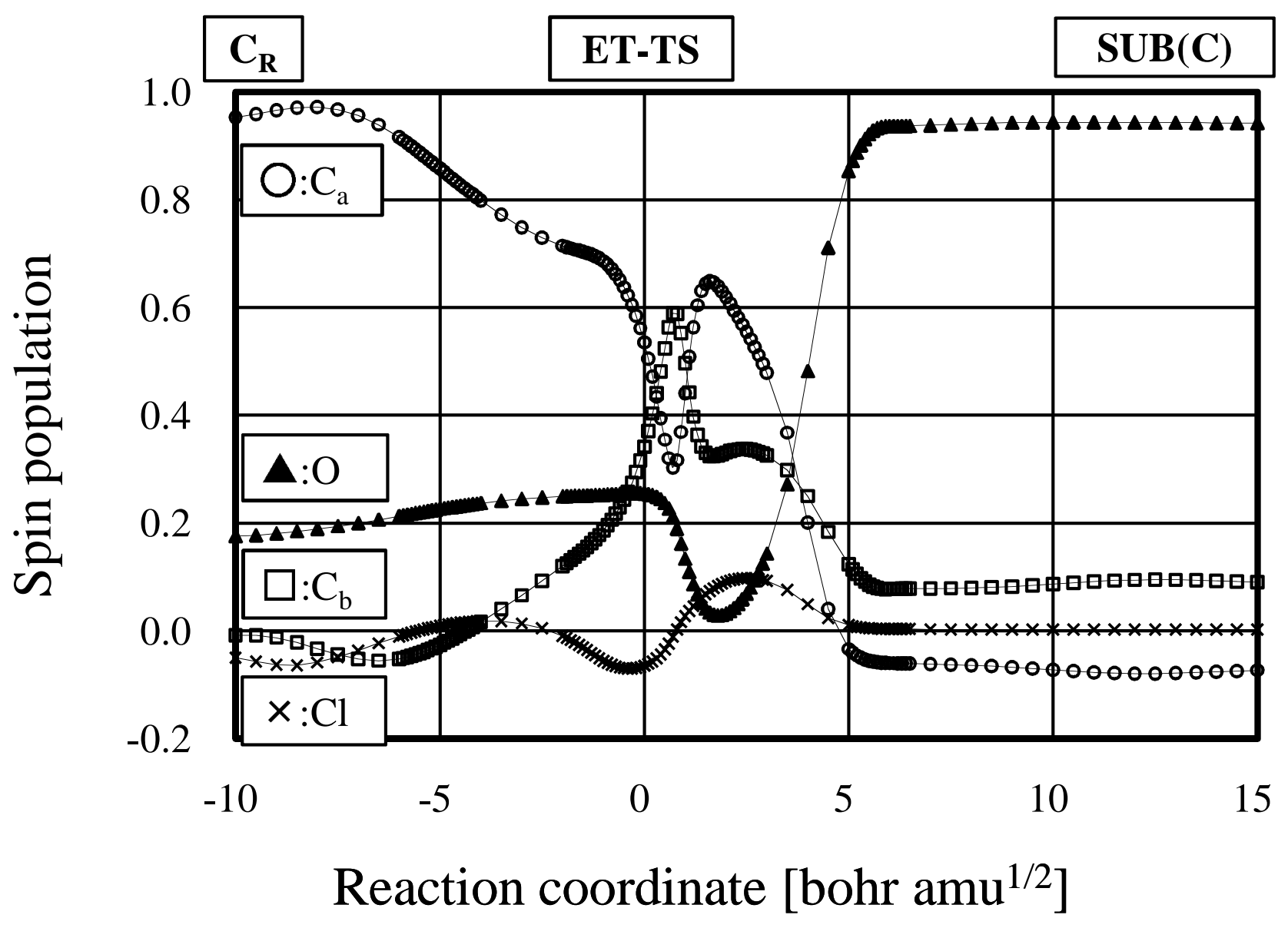


Figure 4

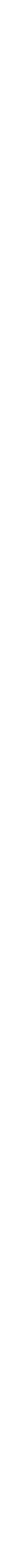

Figure 4 

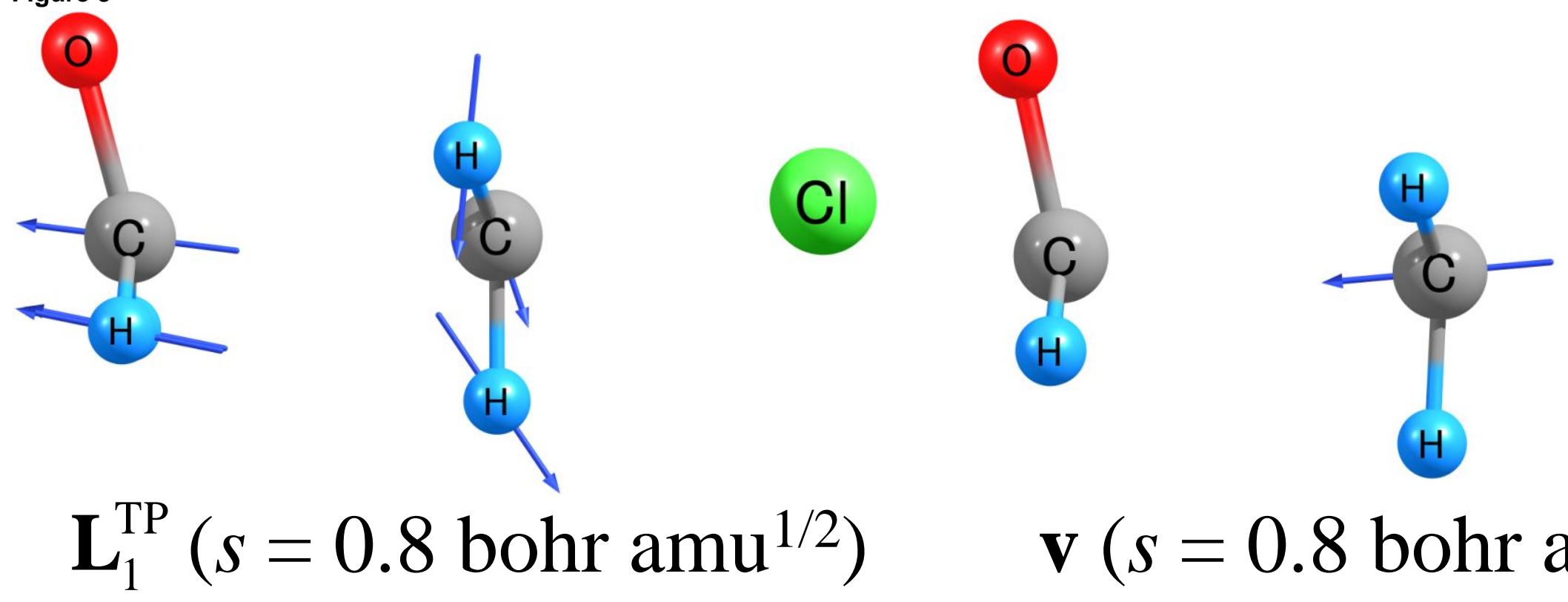

$\mathbf{v}\left(s=0.8\right.$ bohr amu $\left.{ }^{1 / 2}\right)$

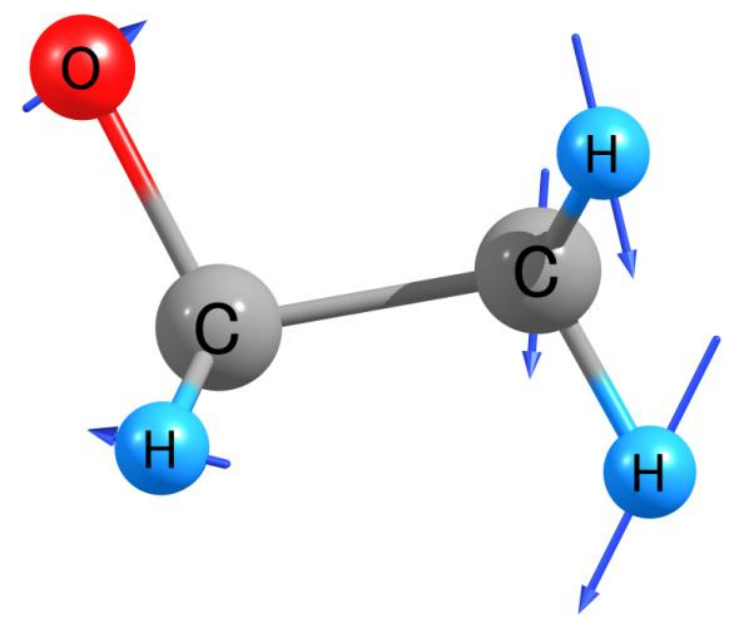

CI

$\mathbf{L}_{1}^{\mathrm{TP}}\left(s=6.0\right.$ bohr $\left.\mathrm{amu}^{1 / 2}\right)$

$\mathbf{L}_{1}^{\mathrm{N}}\left(s=6.0\right.$ bohr $\left.\mathrm{amu}^{1 / 2}\right)$

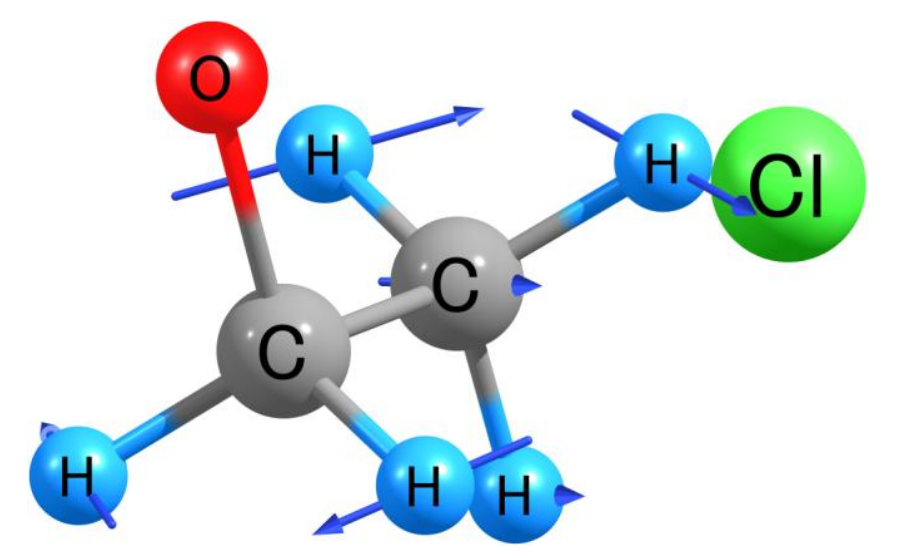




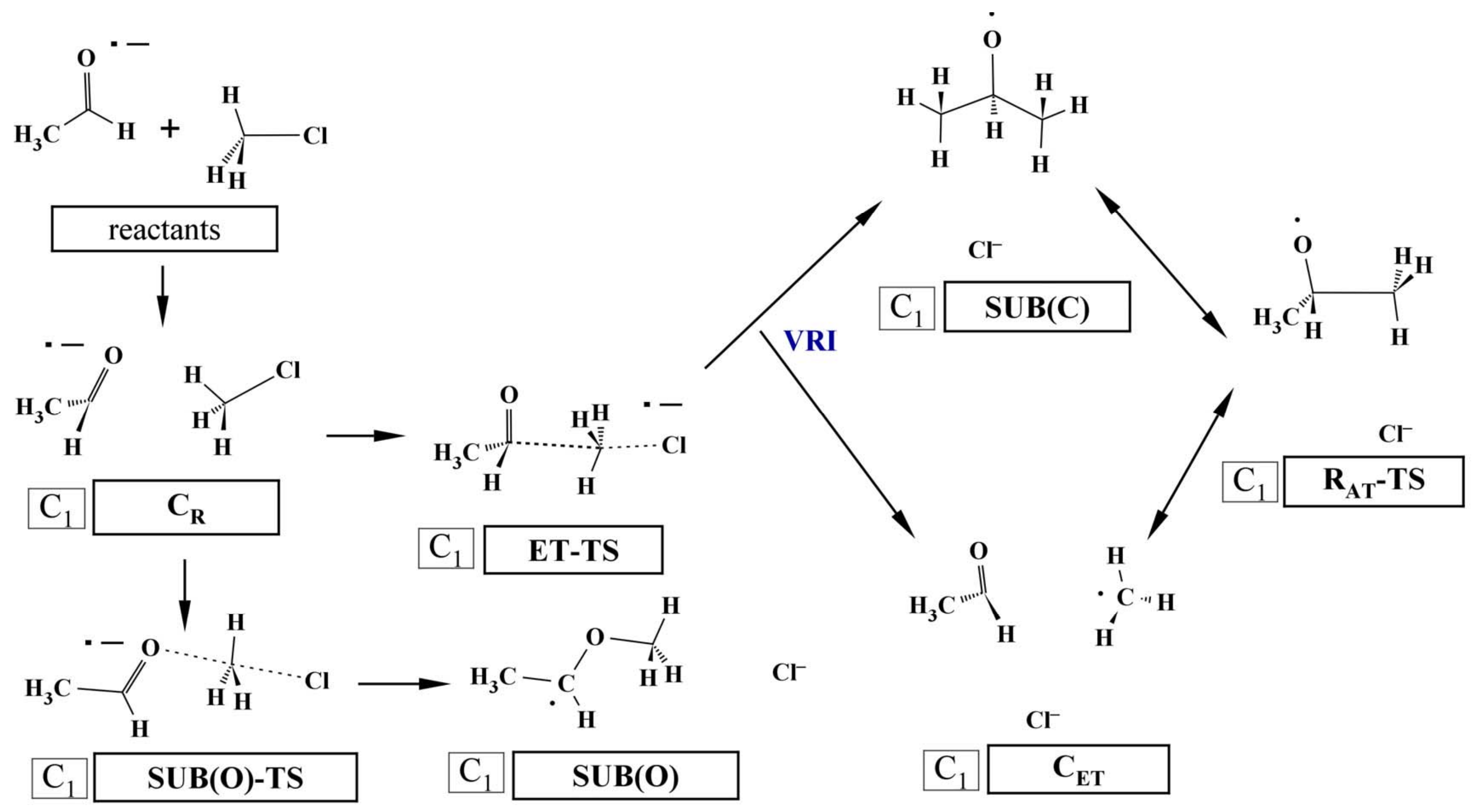


Figure 9

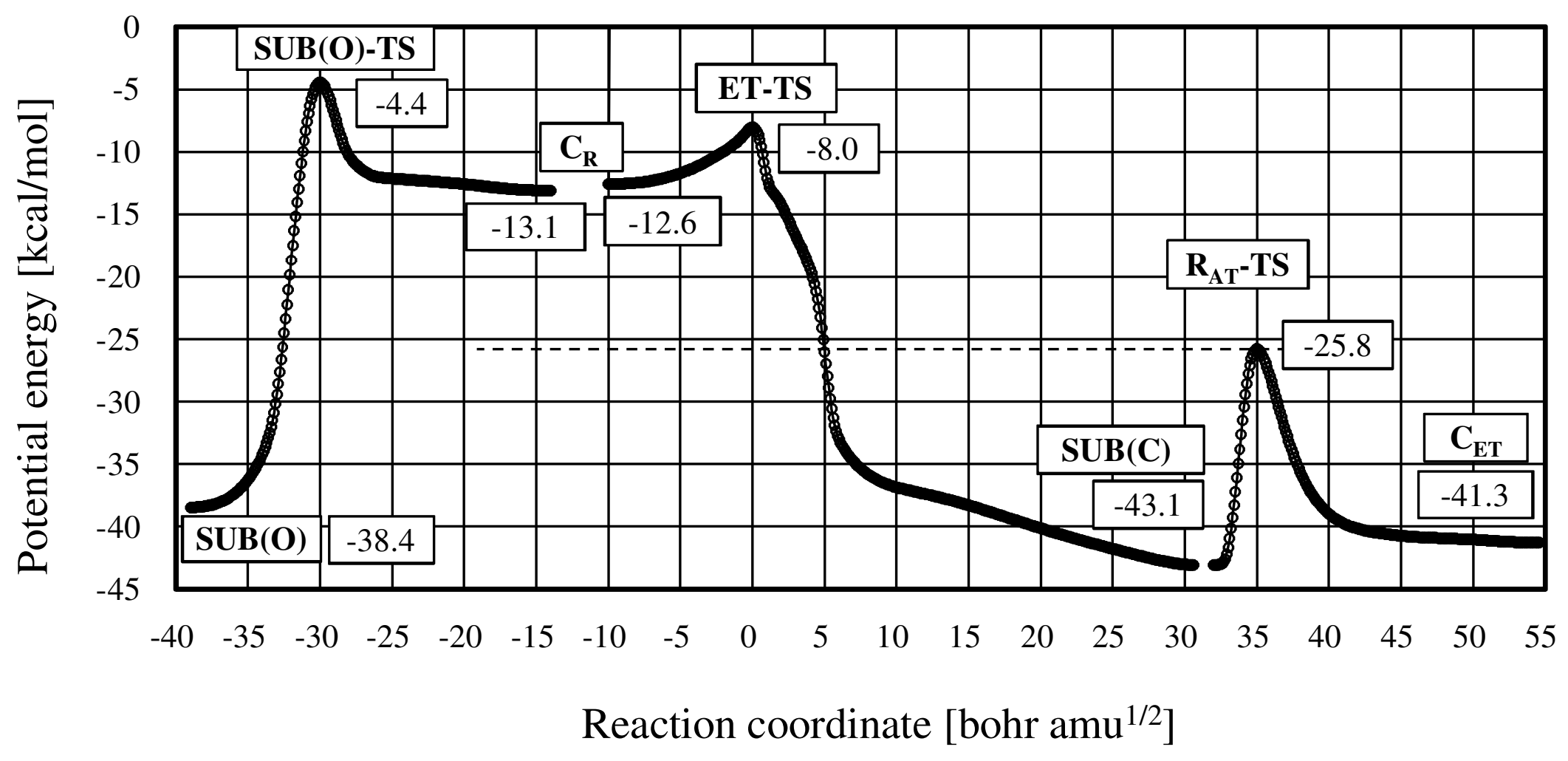




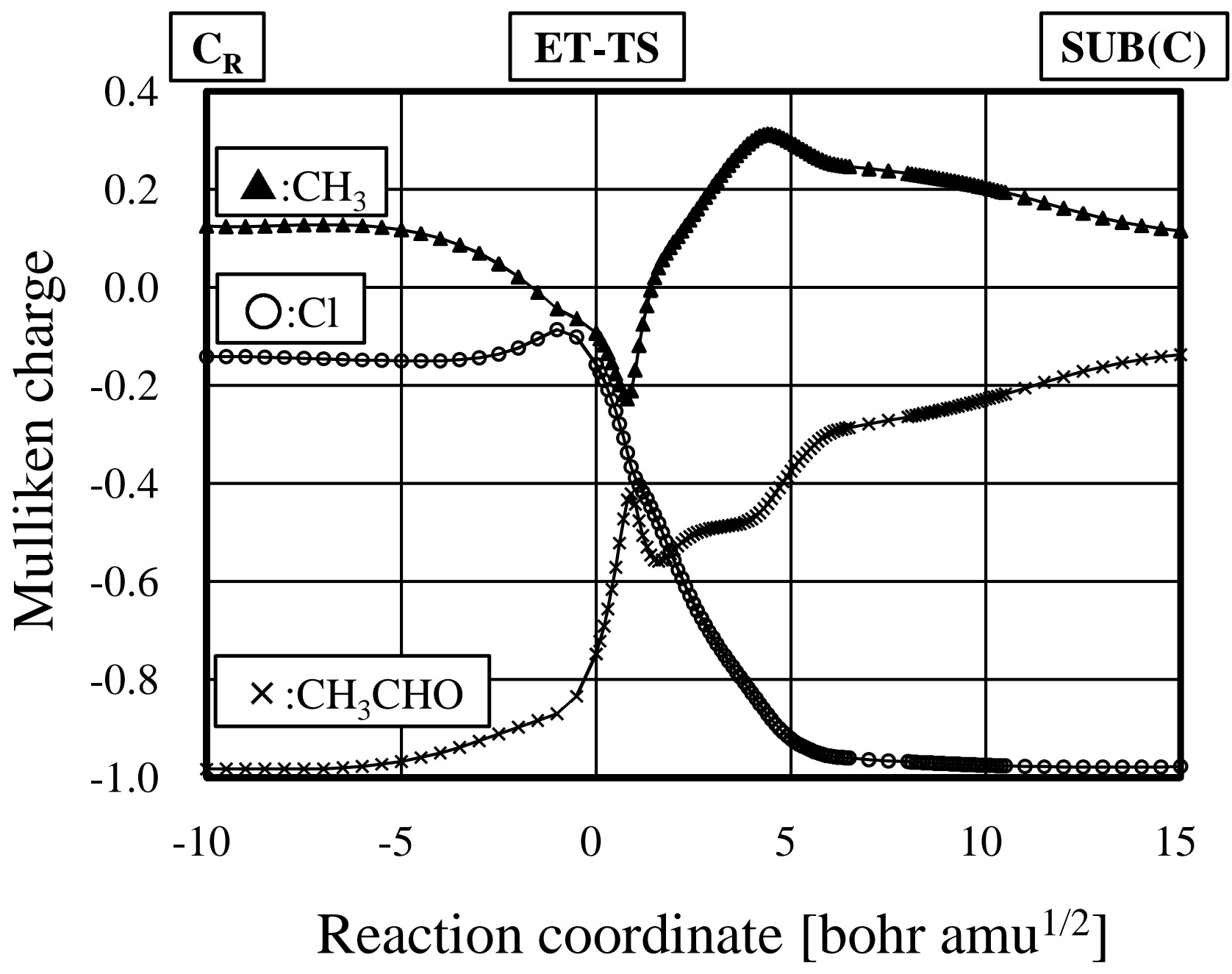




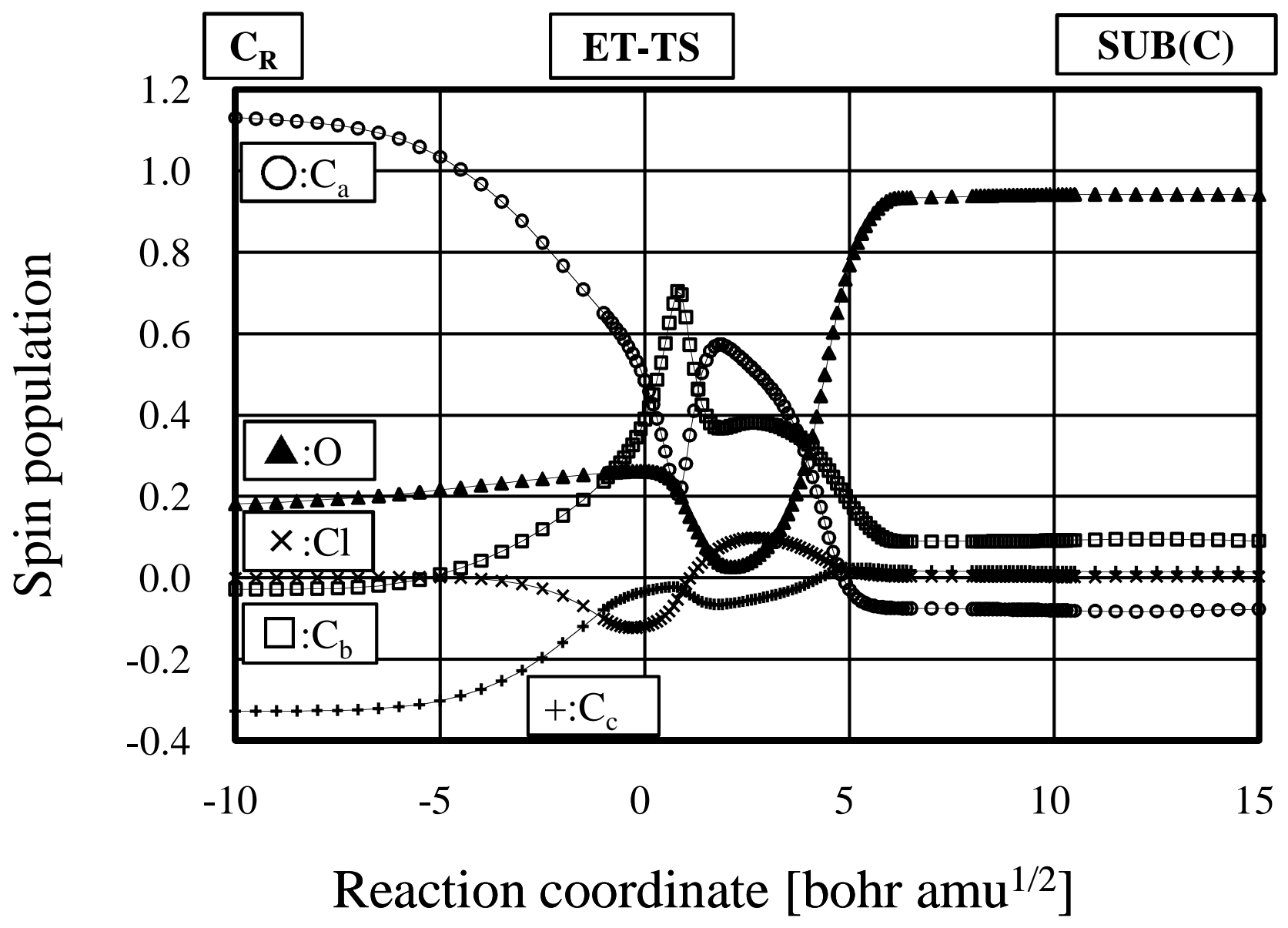




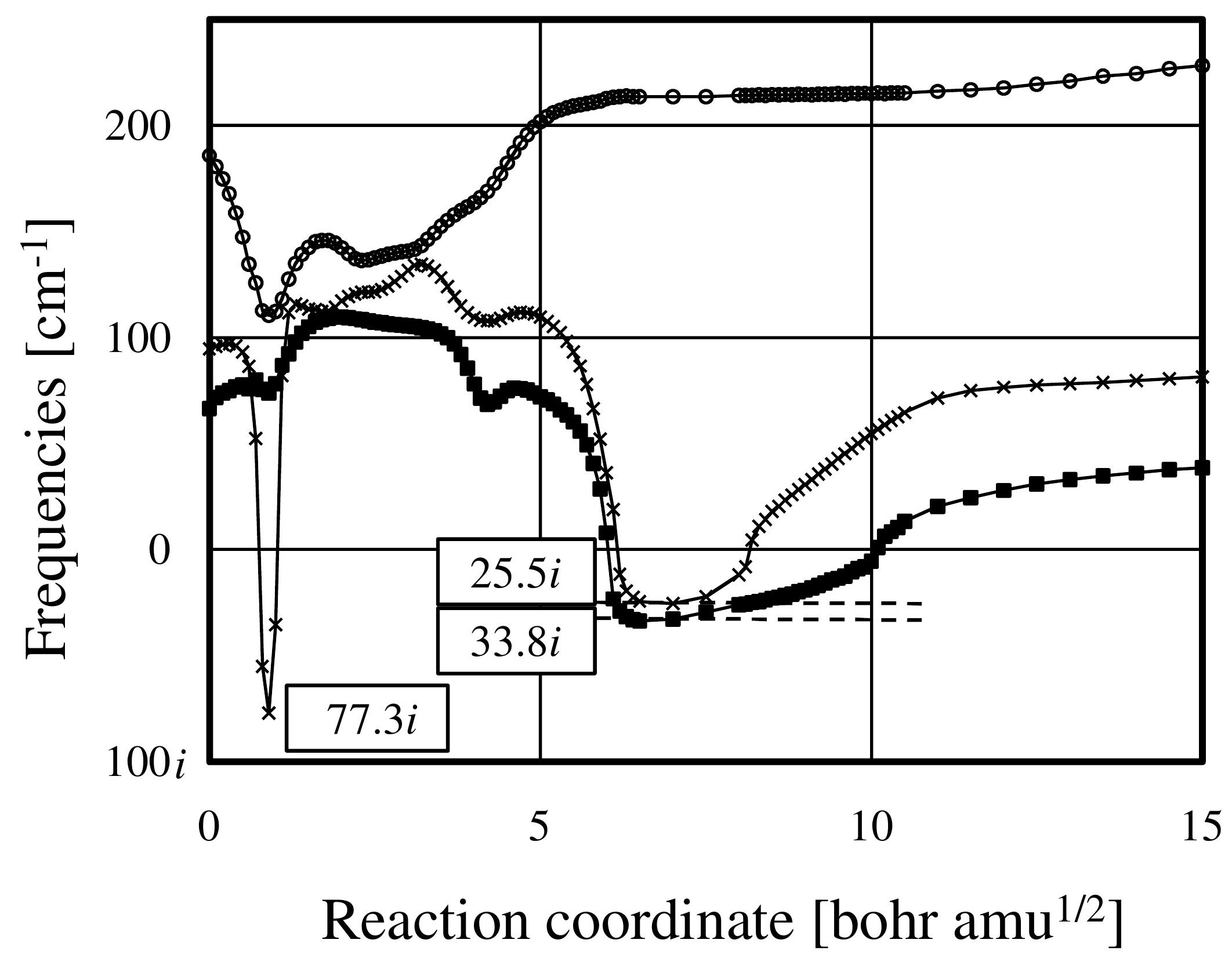

Figure 11 

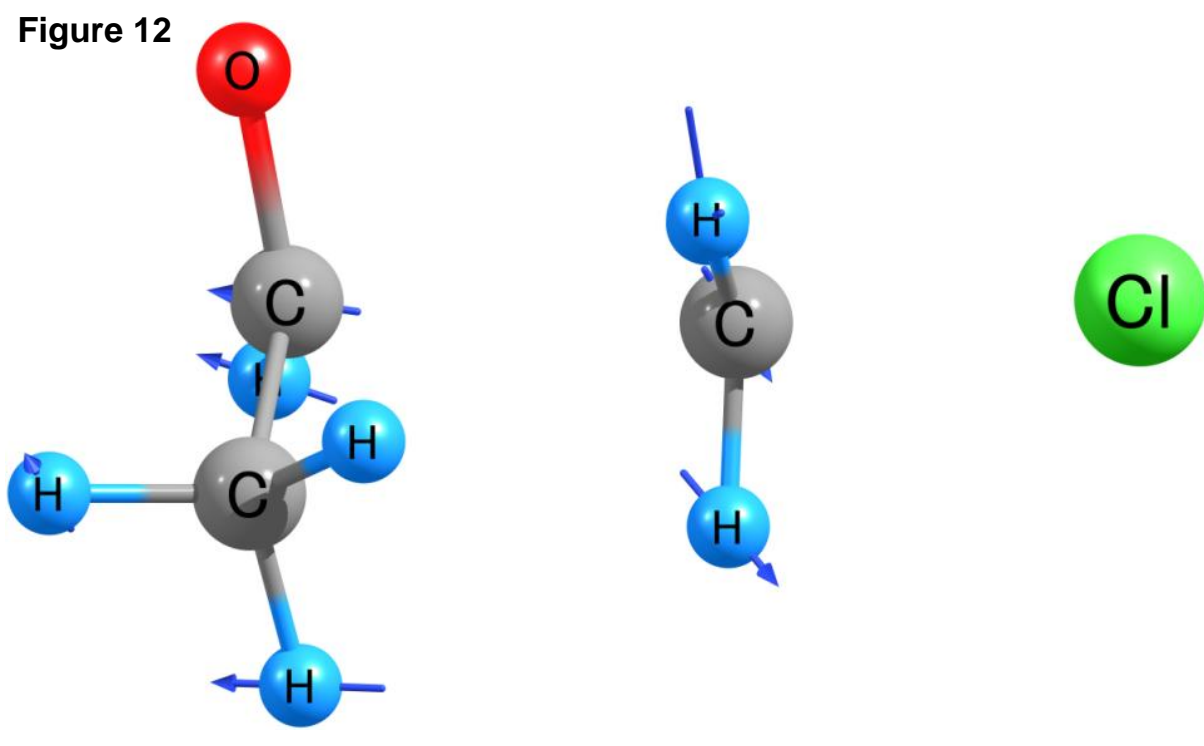

$\mathbf{L}_{1}^{\mathrm{TP}}\left(s=0.9\right.$ bohr $\left.\mathrm{amu}^{1 / 2}\right)$

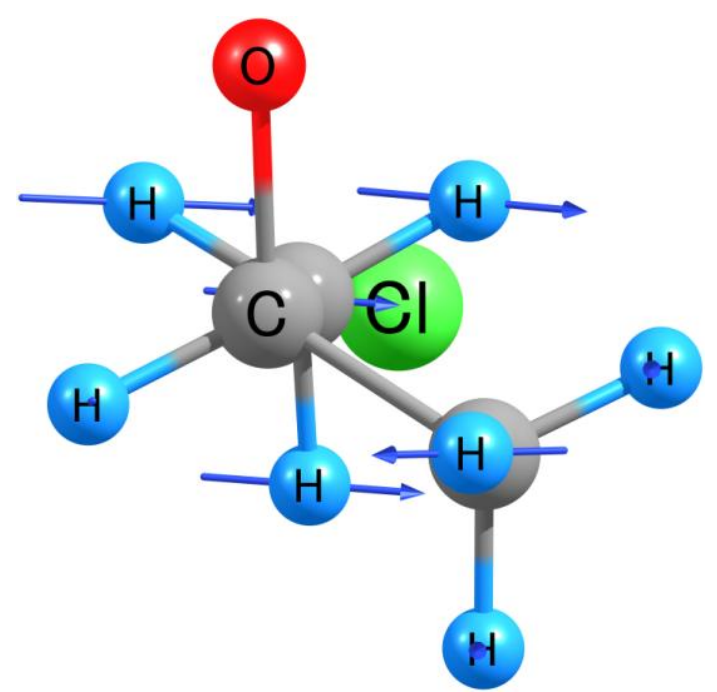

$\mathbf{L}_{1}^{\mathrm{TP}}\left(s=7.0\right.$ bohr $\left.\mathrm{amu}^{1 / 2}\right)$

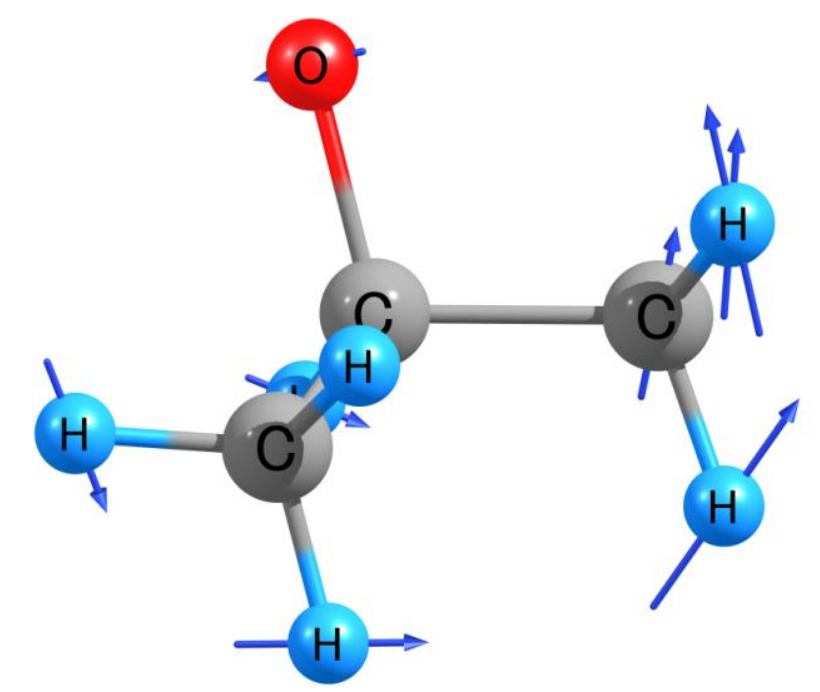

Cl

$\mathbf{L}_{2}^{\mathrm{TP}}\left(s=7.0 \mathrm{bohr}^{\mathrm{amu}}{ }^{1 / 2}\right)$ 


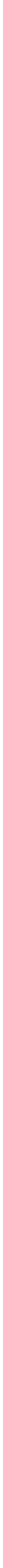

Figure 14

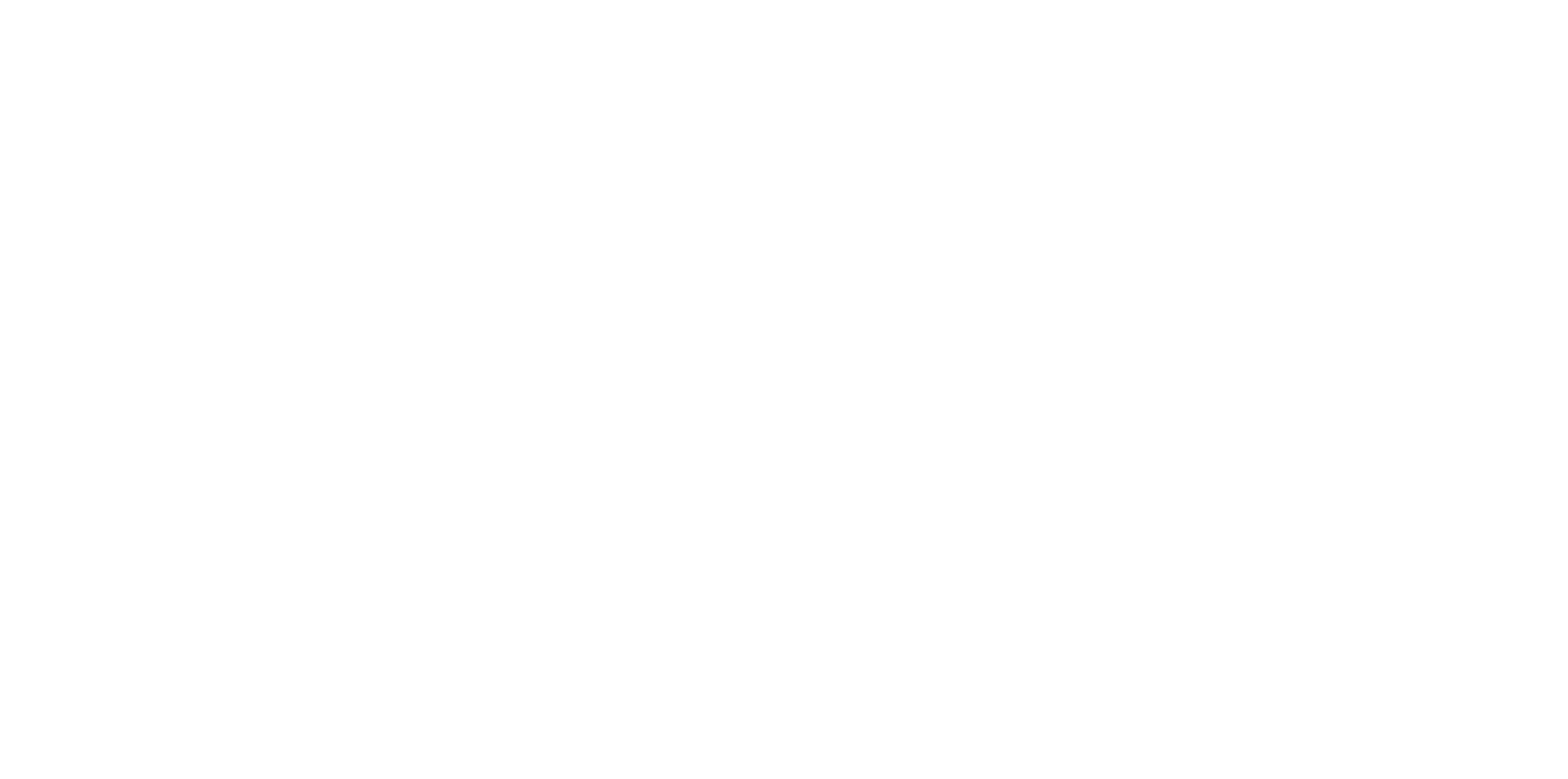

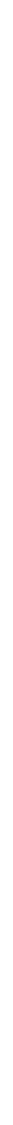

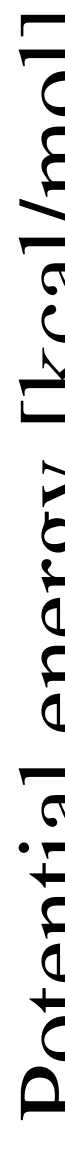

